\title{
LAS ELECCIONES PRESIDENCIALES $Y$ LEGISLATIVAS DE 2002 EN FRANCIA
}

ISABEL M. ${ }^{\circ}$ CANTOS PADILLA

Universidad de Nacional de Educación a Distancia 


\section{SUMARIO}

INTRODUCCIÓN. LAS ELECCIONES PRESIDENCIALES DE 21 DE ABRIL Y DE 5 DE MAYO. I. EL PRESIDENTE dE LA REPÚBLICA EN LA CONSTITUCIÓN DE 1958. I.1. La Presidencia de la V República sigue siendo una Jefatura de Estado parlamentaria. I.2. El Estatuto del Presidente en la Constitución de 1958. II. MOdo de designación DEL PRESIDENTE DE LA REPÚBLICA. II.1. Antecedentes y evolución desde el inicio de la V República. III. ANTECEDENTES DE LA CAMPAÑA ELECTORAL. III.1. Inversión del calendario electoral. III.2. Desarrollo de los meses previos a la campaña electoral. III.3. Precampaña electoral y situación de las fuerzas políticas más importantes. IV. Campaña electoral. IV.1.Candidatos. IV.2. Temas electorales. IV.3. Sondeos. V. LA PRIMERA VUELTA DE 21 DE ABRIL DE 2002. VI. LA SEGUNDA VUELTA DE 5 DE MAYO DE 2002. LAS ELECCIONES LEGISLATIVAS DE MAYO Y JUNIO DE 2002. I. NORMAS APLICABLES A LAS ELECCIONES LEgISLATIVAS. II. CAMPAÑA EleCtORAL. III. LA PRIMERA VUELTA DE 9 DE JUNIO. IV. LA SEgUNDA VUELTA DE 16 DE JUNIO. V. CONCLUSIONES Y VALORACIÓN JURÍDICO-POLITICA. 


\section{LAS ELECCIONES PRESIDENCIALES $Y$ LEGISLATIVAS DE 2002 EN FRANCIA}

POR

ISABEL M. ${ }^{a}$ CANTOS PADILLA

Universidad de Nacional de Educación a Distancia

\section{INTRODUCCIóN}

En este estudio analizaremos las últimas elecciones presidenciales celebradas en Francia, el 21 de abril y 5 de mayo, en primera y segunda vuelta respectivamente, asi como las legislativas de 9 y dieciséis de junio. El punto de referencia que tomaremos serán los resultados de las últimas elecciones municipales, celebradas en marzo de 2001. En ellas se perfiló la situación de la que partirian las distintas fuerzas políticas en su carrera hasta estos comicios clave en los que los franceses han elegido a su Presidente'.

Las elecciones municipales de marzo de 2001 otorgaron un triunfo a la derecha (un $52,48 \%$ frente al $47,50 \%$ de la izquierda), pero modificaron algo el mapa electoral existente hasta entonces. La derecha, ganadora -con resultados incluso mejores que los obtenidos en las municipales de 1995- y con una fuerte base electoral, especialmente en las provincias, perdió sus bastiones más tradicionales, el más sig-

1 Véase mi trabajo "Las elecciones municipales en Francia de 11 y 18 de marzo de 2002", Revista de Estudios Políticos (nueva época), n. ${ }^{\circ} 113$, Centro de Estudios Políticos y Constitucionales, Madrid, 2001. 
nificativo de los cuales, el de la capital, había estado adscrito al tradicionalmente al gaullismo. Por su parte la izquierda, perdedora en las citadas elecciones, logró, como hemos dicho, arrebatar París a la derecha, aprovechando las divisiones de ésta y pactando con los Verdes. También consiguió Lyon, Tulle y Corrèze (ciudad natal de Chirac), gracias a lo cual su derrota quedó amortiguada, al menos simbólicamente. La victoria de la derecha en las elecciones municipales de abril iniciaría una inversión en la tendencia al equilibrio de las dos principales fuerzas politicas (derecha parlamentaria e izquierda plural) observada en las elecciones presidenciales de 1995, tendencia que se confirmaría en las legislativas de 1997, en las regionales de 1998 y finalmente en las europeas de 1999, y que veremos nuevamente confirmada en las elecciones presidenciales que ahora nos ocupan. La poca rotundidad de los resultados de las elecciones municipales del pasado año, daría lugar a una especie precampaña cuyo comienzo puede situarse en el mismo momento en que finalizaron los citados comicios ${ }^{2}$. De dichos resultados, podian extraerse en cambio importantes conclusiones sobre los deseos del electorado. El voto de la población, que demostró su preferencia por candidatos con implantación local sobre las grandes figuras de la política nacional ${ }^{3}$ y por otros candidatos que encabezaban listas alternativas de izquierda, a veces de mero carácter asociativo ${ }^{4}$, daba ya a entender el deseo de algunos sectores sociales, en especial de los más desfavorecidos, de identificarse con políticos que pudieran resolver sus problemas concretos, y no ya tanto con aquéllos que seguían debatiendo los grandes temas nacionales o europeos. A esto hay que sumar las diferencias, no sólo șociales, étnicas

2 La incertidumbre arrojada por estos resultados ha motivado que no hayan podido servir de mucha ayuda para predecir los resultados de las dos grandes citas electorales de 2002, como es habitual hacer con este tipo de elecciones menores, sobre todo porque en aquellas participan políticos de primera línea que aparecen después en las elecciones legislativas, gracias a la posibilidad de acumulación de mandatos, limitada sólo parcialmente por la LO n. ${ }^{\circ} 2000-294$ de 5 de abril. Sin embargo, el voto de los electores en las citadas elecciones de 2001 demostró que éstos preferían a los candidatos con implantación local sobre las grandes figuras de la politica nacional.

3 Recordemos la derrota de Elisabeth Gigou, Ministro de Justicia, en Avignon, y de Jack Lang, Ministro de Educación Nacional, en Blois, así como la victoria, muy ajustada, de Martine Aubri en Lille, pese a haber dejado el Gobierno de la Nación para combatir por la citada alcaldía.

4 Ya comentamos en nuestro artículo sobre esas municipales (véase supra, pág. 397) el nacimiento de listas asociativas de izquierda como los "Motivé-e-s" y de la persistencia y ligera progresión de la LO, la LCR y el PT. 
o religiosas, sino culturales; por ejemplo las existentes entre la clase obrera, los pequeños artesanos, comerciantes, o agricultores, mayoritarios en el conjunto de la población, y los cuadros medios y superiores. Estas diferencias parecen haber ido más rápido que las respuestas de los políticos de los principales partidos, en definitiva, que las medidas estatales que debian solucionar dichas diferencias ${ }^{5}$. En las páginas siguientes veremos que en las recientes elecciones presidenciales, este descontento del electorado se ve claramente confirmado en la desconcertante subida de la extrema derecha liderada por Le Pen y en la multiplicación de candidatos de todos los signos, muchos de ellos de extrema izquierda.

\section{LAS ELECCIONES PRESIDENCIALES DE 21 DE ABRIL Y DE 5 DE MAYO}

\section{EL PRESIDENTE DE LA REPÚBLICA EN LA CONSTITUCIÓN DE 1958}

\section{I.1. La Presidencia en la V República sigue siendo una Jefatura de Estado parlamentaria}

La Constitución francesa de 1958 concibe un modelo de ejécutivo bicéfalo, integrado por el Jefe del Estado, al que corresponde una posición preeminente, y el Gobierno, a cuya cabeza está un Primer Ministro, que aquél nombra, pero que sin embargo debe contar con la confianza de la Asamblea para poder gobernar. En esto la Constitución

5 En este sentido véase el análisis de KAUFMANN, Jean-Claude, sociólogo y director de investigación del CNRS (Centro nacional de investigación científica), realizado para Le Monde, (26 de abril de 2002, pág. 12): "Francia (como el resto de países desarrollados) se divide en dos. Ya no socialmente, como ocurría antes, sino culturalmente $y$ de forma irremediable". En efecto, este analista apunta que la modernidad intelectual es un fenómeno que sigue siendo socialmente minoritario. Sobre todo si el análisis se amplía geográficamente. Asimismo señala -y esto creo que explica perfectamente el hasta entonces casi impredecible fenómeno politico acaecido en las pasadas elecciones presidenciales - que, cuanto mayor es la acumulación de nuevos conocimientos en individuos culturalmente dotados $y$ cuanto más dicho conocimiento transforma a estos individuos en centros de reforma permanente de su propia existencia, mayor es el abismo que los separa de aquéllos que se buscan les proteja y diferencie del exterior valiéndose de una tradición, como antaño. 
de 1958 sigue la estructura institucional adoptada desde la III República. Al mismo tiempo intenta crear un Ejecutivo fuerte, que no esté supeditado a los vaivenes parlamentarios, y para ello lo dota de los instrumentos necesarios: al Presidente le atribuye importantes prerrogativas, de las que la más trascendente es sin duda la facultad de disolver el Parlamento (art. 12), mientras que al Gobierno le proporciona determinadas armas con las que gobernar en ausencia de una mayoría estable en la Asamblea, mediante la puesta en práctica de lo que se conoce como parlamentarismo racionalizado ${ }^{6}$. En esto la Constitución de 1958 rompe con su antecesora de 1946. Simbólicamente deja constancia de ello presentando primero los Títulos dedicados al Presidente y al Gobierno y después el destinado al Parlamento (solución inversa a la seguida en texto de 1946). Sin embargo, si alguien que desconozca la práctica política francesa posterior a 1958 analiza la Constitución francesa vigente, centrándose exclusivamente en el texto, verá que el régimen concebido por ésta es, pese a sus desviaciones del esquema clásico, auténticamente parlamentario y que los poderes conferidos al Presidente no distan mucho de los que literalmente le atribuía la Constitución de 1875; ahora bien, la práctica política ha hecho del papel del Presidente, durante la vigencia de una y otra, realidades casi diametralmente opuestas ${ }^{7}$. En efecto, la trayectoria seguida por la institución presidencial desde la promulgación de la Constitución en 1958 hasta las elecciones legislativas de 1986, con las que se inicia la primera diarquía, demuestra que los poderes del Presidente de la República pueden sobrepasar ampliamente los que le concede la Constitución cuando la mayoría que lo ha llevado a la Presidencia coincide con la de la Asamblea, porque entonces él es el auténtico jefe de ambas. Con la revisión constitucional de 1962, tras la que el Presidente es elegido por sufragio universal directo, de Gaulle viene a legitimar erróneamente esta práctica ${ }^{8}$, consciente de que sus

\section{Cfr. nota 12, infra.}

7 En este sentido véase CHATELAIN, Jean, "Titre premier: De la Souveranité", en LUCHAIRE, François, y CONAC, Gérard, La Constitution de la République française, 2. ${ }^{8}$ ed., París, Economica, 1987, pág. 190.

8 Coincidimos con Philippe ARDANT en que la revisión de 1962 sólo contribuye a reforzar la auctoritas del Jefe del Estado y no a aumentar sus atribuciones. La elección por sufragio universal directo tiene como principal objetivo aumentar su legitimidad y alejar su elección de las intrigas partisanas (cfr. ARDANT, Philippe, Institutions politiques et droit constitutionnel, 11. ${ }^{\text {a }}$ ed., Librairie générale de droit et de jurisprudence, E.J.A., 1999, págs. 443 y 460 ). La elección mediante sufragio universal directo legitima la autoridad del Presidente como institución, porque gracias a la misma él cuenta con la confianza explícita de la nación, pero no por ello 
sucesores en la Presidencia no contarán con su misma legitimidad histórica, reforma que contribuirá a que el régimen se califique de semipresidencial o de semi-parlamentario ${ }^{9}$. Por nuestra parte pensamos que el régimen constitucional francés es auténticamente parlamentario desde el punto de vista jurídico, si bien, desde el punto de vista político es sólo parlamentario en período de cohabitación. Por consiguiente, a nuestro juicio, la calificación del régimen como semi-presidencial o semi-parlamentario tiene el inconveniente de su parcialidad, pues califica el régimen sólo desde el punto de vista político y dentro de una coyuntura política determinada, a saber: la coincidencia de mayorías presidencial y parlamentaria. Por lo tanto hay que esperar a la primera diarquía para empezar a ver un funcionamiento de las instituciones más acorde con el texto constitucional: la aparición de una nueva mayoría en la Asamblea, hostil a la del Presidente, da paso a una nueva situación en la que los distintos centros de poder se ven obligados a volver la vista al texto constitucional para agotar al máximo todas las posibilidades que éste les ofrece. A partir de este momento queda demostrado que la concordancia o discordancia de mayorías (presidencial y parlamentaria) marca en la praxis -que no en lo jurídico, como ha quedado dicho - el máximo y el mínimo de la función presidencial y que es durante la diarquía cuando la coincidencia entre texto y praxis es más completa ${ }^{10}$.

\section{I.2. El Estatuto del Presidente en la Constitución de 1958}

El título II no contiene ninguna disposición, fuera del artículo 6 (duración del mandato) y del artículo 68 (irresponsabilidad del Jefe del

legitima una la práctica política que se sale de la letra de la Constitución. En este sentido cfr. ARDANT, Philippe, "L'article 5 et la fonction présidentielle" (en VV.AA., "Le Président», en Pouvoirs, n. ${ }^{\circ} 41$, París, Presses Universitaires de France, 1987, pág. 49).

9 Otros como CADART, Jacques, califican este régimen como monarquía parlamentaria republicana, asimilándola a las monarquías parlamentarias dinásticas del siglo XIX (cfr. CADART, Jacques, "La monarchie parlamentaire républicaine et la répresentation proportionnelle", en Pouvoirs, París, Presses Universitaires de France, v. 32 1985, pág. 119).

10 Como dice Gérard Conac (cfr. "Titre II: Le Président de la République, Article 5", en LuCHAIRE, François, y ConAC, Gérard, La Constitution de la République française, 2. ${ }^{a}$ ed., París, Economica, 1987, pág. 273): «En períodos de cohabitación el Presidente de la República pierde en efecto los poderes políticos que 
Estado). Sin embargo, al margen de estas dos disposiciones, el mandato presidencial es objeto de protección legislativa, reglamentaria y consuetudinaria. A continuación nos referiremos brevemente a las principales normas que integran este estatuto.

\subsubsection{Duración del mandato presidencial}

El mandato presidencial es de cinco años tras la reforma del artículo 6 llevada a cabo en $2000^{11}$, que modificó sólo en este punto su redacción anterior - que establecia un mandato de siete añosmediante un proyecto de Ley constitucional aprobado por ambas Cámaras y ratificado posteriormente en el referéndum celebrado el 24 de septiembre de $2000^{12}$. La nueva redacción del artículo 6 re-

tenía del sostén de una mayoría parlamentaria, para conservar sólo los constitucionales».

11 La reducción del mandato presidencial ya la habian considerado anteriormente Pompidou en 1973, Giscarg d'Estaing en 1974 y Mitterrand, la víspera de las elecciones de 1988 y en 1993, en una carta dirigida al Comité constitucional, creado por él.

12 Se siguió así uno de los tres procedimientos de reforma constitucional establecidos como posibles por el articulo 89, que respondió a la secuencia: iniciativa presidencial (a propuesta del Primer Ministro), aprobación en ambas asambleas y ratificación en referéndum. Esta solución de aprobación final del texto mediante referéndum, supuesto normal o subsidiario del de la decisión expresa - de competencia exclusivamente presidencial - de someterlo a la aprobación del Parlamento convocado en Congreso, ha sido en cambio muy poco utilizada, hasta el punto de haber sido ésta la primera vez que una reforma constitucional ha prosperado por este medio. En efecto, el Ejecutivo ha excluido de forma sistemática esta vía de consulta popular, prefiriendo recurrir, de forma poco ortodoxa desde el punto de vista jurídico, a la consulta referendaria por la vía del artículo 11, que permite al Ejecutivo el recurso directo al arbitraje popular, vetando así el poder constituyente a la Asamblea Nacional. El primer caso de utilización del referéndum para una revisión constitucional fue precisamente en 1962, cuando De Gaulle recurrió a él para solicitar directamente al pueblo que en lo sucesivo el Presidente de la República fuera elegido mediante sufragio universal directo, omitiendo así todo un título de la Constitución, el XVI, titulado «Sobre la revisión", y acudiendo al Título II, dedicado al Presidente de la República (sobre la controversia jurídica que suscitó esta impropia utilización del artículo 11 durante la V República y sobre el problema de fondo consistente en complementar las técnicas referendarias o de democracia directa y las parlamentarias en un Estado democrático moderno véase el artículo de ConAC, Gérard, "Les débats sur le référendum sous la Ve République», en Pouvoirs, v. 77, Paris, Seuil, 1996, págs. 95-108. Asimismo, "Le Président de la République - Article 11», en LuCHAIRE, 
toma la idea del proyecto Pompidou de 1973. Los motivos que entonces inspiraron a éste son diferentes de los que ahora, transcurridas casi tres décadas, han conducido finalmente a esta reforma ${ }^{13}$. Las razones aducidas esta vez para la sustitución del septenato por el quinquenato han sido múltiples. Una de ellas es la de que el septenato no guarda ya ninguna relación con el motivo por el que se concibió en el siglo $\mathrm{XIX}^{14}$, época desde la que se ha venido manteniendo por razones meramente circunstanciales. Ya en la V República resultó de utilidad en determinadas épocas, especialmente durante los períodos en los que eran frecuentes las crisis ministeriales. La mayor duración de la función presidencial, junto con la reforma llevada a cabo en 1962, facilitaba una estabilidad en las instituciones que los sucesivos gobiernos no podrían ofrecer ${ }^{15}$. Pero esa mayor duración del mandato podía llevar más fácilmente a situaciones de antagonismo entre la Presidencia de la República y la Asamblea Nacional, a menos que el Presidente intentase conciliar ambas expresiones de soberanía popular disolviendo la Asamblea para convocar asi nuevas elecciones legislativas ${ }^{16}$. Por lo tanto, la función del quinquenato sería la de reducir el riesgo de una cohabitación, mediante la celebración, dentro de un mismo breve período, las elecciones presidenciales y las legislativas y, de ese modo, fortalecer la institución presidencial, debilitada por sucesivas cohabitaciones. En definitiva, entre las dos posibles lecturas de la Constitución, la

François, y CONAC, Gérard (dir.), La Constitution de la République française, 2.a ed., 1987, págs. 484 y ss.).

13 Para G. Pompidou, el papel del Presidente en la V República era demasiado importante como para ser revalidado sólo cada siete años. También por entonces Georges Vedel denunciaba la falta de adecuación de la duración de este mandato, pensado para la III República, a la institución presidencial tal como la concebía la Constitución de 1958, sobre todo teniendo en cuenta la larga lista de poderes presidenciales que ésta contiene (cfr. GUCHET, Yves, La Ve République, 3." ed., París, Economica, 1994, págs. 92 y ss.). 1875.

14 Fue con ocasión de la adopción de las leyes constitucionales del año

15 Code constitutionnel commenté et annoté, Th. S. Rénoux y M. DE Villiers, 2. ${ }^{a}$ ed., pág. 299. Esta mayor duración del mandato era conforme con la idea de la República de de Gaulle, ya apuntada en el discurso de Bayeux, es decir, la de un Presidente a la cabeza del Ejecutivo, actuando como árbitro nacional, concepción que quedó plasmada en el artículo 5 del texto constitucional, precepto éste considerado como la clave interpretativa del edificio constitucional de la $\mathrm{V}$ República.

16 Paradójicamente, una de esas disoluciones, la de Chirac de 1997, creó una cohabitación en lugar de eliminarla. 
presidencial y la parlamentaria, se trataria de dar prioridad a la primera17.

La doctrina no es unánime sobre la eficacia del quinquenato. Para algunos la casi simultaneidad de ambas elecciones puede prácticamente asegurar la concordancia de ambas mayorias, presidencial y parlamentaria ${ }^{18}$. Para otros el quinquenato anula implícitamente una de las formas de expresión del pueblo francés y, además, no descarta totalmente la cohabitación, porque, entre otros factores, la proximidad de ambas elecciones, conseguida para las elecciones de 2002, podría verse alterada en lo sucesivo por factores como la dimisión del Presidente o la disolución de la Asamblea ${ }^{19}$.

El mandato presidencial comienza el día en el que el Consejo constitucional proclama los resultados de la elección presidencial. Si mientras tanto sobreviene impedimento o vacancia, el Senado asegurará el ínterin $y$, en caso de impedimento de éste, será ejercido por el Gobierno (cfr. art. 7) ${ }^{20}$. También puede el presidente saliente, según el Consejo constitucional, anticipar el final de su mandato21.

17 Por lo tanto, se podría hablar de un presidencialismo racionalizado. Ahora bien, el tema de fondo sigue radicando, para muchos autores, en la cuestión de hasta dónde se puede fomentar la presidencialización de la $V$ República sin poner en peligro su estructura parlamentaria. Cfr. Code constitutionnel commenté et annoté, op. cit., pág. 300 .

18 Cfr. MASSOT, Jean, «Réfomer la Constitution pour éviter la Cohabitation? C'est necessaire et possible», en "La Cohabitation", Pouvoirs, n. ${ }^{\circ} 91$, Presses Univrsitaires de Frances, 1999, pág. 136.

19 Cfr. François LuCHAIRE, "Réformer la Constitution pour éviter la Cohabitation? C'est inutile", en "La Cohabitation", Pouvoirs, n. ${ }^{\circ} 91$, París, Presses Universitaires de France, 1999, págs. 119-127. En efecto, este autor, favorable a la cohabitación y partidario del septenato no renovable, apunta que cuando las elecciones presidenciales y legislativas tienen lugar con cierta proximidad, el voto de la segunda elección se ve condicionado por el de la primera. Un ejemplo lo encontramos en 1981 y 1988, años en los que las elecciones presidenciales antecedieron en pocos dias a las legislativas. Si, por el contrario, para no condicionar dicha expresión popular, las elecciones se celebraran el mismo día, la ausencia de condicionantes previos podría facilitar que los electores votaran por una cohabitación. Por el contrario, si se celebraran con más separación, se viviría en una situación de permanente campaña electoral.

20 Durante este mandato interino, cuyo objetivo no es otro que mantener la continuidad de los poderes públicos. En lógica correspondencia con el carácter interino de esta situación, la Constitución impone determinadas restricciones, consistentes en neutralizar durante este período los artículos 11, 12, 49, 50 y 89.

21 Cfr. Code constitutionnel commenté et annoté, a cargo de Th. S. RÉNOUX y M. DE VilLiers, 2. ${ }^{a}$ ed., pág. 301. 


\subsubsection{Responsabilidad del Jefe de Estado francés en la Constitución de 1958}

El artículo 68 establece la irresponsabilidad del Presidente de la República salvo en el caso de alta traición, de la que sólo responde ante el Alto Tribunal de Justicia22. En defecto de definición legal o constitucional sobre qué debe entenderse por alta traición, la doctrina ${ }^{23}$ considera que debe considerarse alta traición la violación grave de los deberes inherentes al cargo de Presidente, lo que remite a la definición que de los mismos realiza el artículo 5 de la Constitución ${ }^{24}$.

El problema estriba, no en la irresponsabilidad política o penal del Presidente durante el ejercicio de su cargo, que es total, salvo en el citado supuesto de alta traición, sino en determinar si esta irresponsabilidad alcanza a los actos anteriores y posteriores al desempeño de dicho cargo. Este tema ha estado en el trasfondo de las elecciones presidenciales que ahora analizamos y en el de las municipales del año anterior en relación con el presidente saliente Jacques Chirac, lo que ha motivado la adopción de proyectos de revisión, en mayo de 2001, destinados a hacer posible que el Presidente pueda ser encausado durante el ejercicio de su cargo ante los tribunales ordinarios ${ }^{25}$. Respecto de la situación normativa vigente, el Consejo Constitucional reconoció al Presidente de la República una inmunidad general que venía a consagrar en la práctica su irresponsabilidad también en estos supuestos, afirmando que el Presidente de la República, durante el ejercicio de sus funciones, sólo podía ser

22 En efecto, el artículo 68 dispone: “El Presidente de la República no es responsable de las acciones realizadas en el ejercicio de sus funciones, salvo en el caso de alta traición. No puede ser enjuiciado más que por las dos asambleas estatuyendo por medio de un voto idéntico en un escrutinio público y con el voto de la mayoría absoluta de los miembros que la componen. Es enjuiciado por el Alto Tribunal de Justician.

23 Cfr. Code constitutionnel, op. cit., pág. 622.

24 Artículo 5: «EI Presidente de la República vela por el respeto de la Constitución. Asegura, con su arbitraje, el regular funcionamiento de los poderes públicos asi como la continuidad del Estadon.

Es el garante de la independencia nacional, de la integridad del territorio, del respeto de los acuerdos de Comunidad y de los tratados".

25 En efecto, el nombre de Jacques Chirac, cuando era alcalde de París antes de 1995, ha aparecido en varios procedimientos judiciales, lo que ha hecho que el problema se plantee, no como un caso hipotético, sino como algo real y concreto. 
encausado ante el Alto Tribunal, reconociéndole así un privilegio de jurisdicción ${ }^{26}$.

Respecto de la responsabilidad política del Presidente francés, el Parlamento no dispone de ningún medio para obligarle a dimitir, sino que sólo puede, a lo sumo, revocar al Gobierno nombrado por él. Por lo tanto, una vez más, el único medio de exigir responsabilidad al Presidente, es por medio del artículo 68. Si existe en cambio, como dice García Canales, una responsabilidad política difusa ${ }^{27}$, que se verifica en la sanción que el electorado realiza de la gestión del presidente, como único medio de compensar la brecha que deja la combinación del estatuto de irresponsabilidad presidencial con el amplio elenco de poderes o funciones presidenciales dispensados de refrendo.

\subsubsection{Otras reglas que configuran el estatuto del Presidente}

Fuera de las normas constitucionales citadas, del cuerpo normativo francés aplicable al Presidente de la República se desprende que el Presidente debe consagrarse a su función, de forma que la incompatibilidad entre el mandato presidencial y cualquier otro tipo de función pública o privada debe considerarse absoluta, si bien dicha regla no reposa en ningún texto ${ }^{28}$. Asimismo, para el desempeño de sus funciones el Presidente está rodeado de un equipo de órganos colaboradores, a saber: la Secretaría general, que desempeña una función de información, de preparación de expedientes y de seguimiento de ejecución de decisiones y que se ocupa de las relaciones con los ministerios y las administraciones, medios políticos, económicos y sindicales y la prensa y cuyo dirigente, el Secretario general, es el colaborador más estrecho del Presidente; el Gabinete, con una función menos política que se ocupa de la vida interior del Elíseo; $Y$, finalmente, el estado mayor particular, que asiste al Presidente en sus atribuciones de Jefe del Ejército.

26 Decisión n. ${ }^{\circ}$ 98-408 DC de 22 de enero de 1999 , cons. 15 y 16. Cfr. Recueil de jurisprudence constitutionnelle 1994-1999, a cargo de FAvOREAU, Louis, París, Litec 2000, pág. 806.

27 Cfr. García CAnales, Mariano, La Monarquía parlamentaria española, Madrid, Editorial Tecnos, 1991, pág. 132.

28 Cfr. Code constitutionnel commenté et annoté, op. cit., pág. 301. 


\section{MODO DE DESIGNACIÓN DEL PRESIDENTE DE LA REPÚBLICA}

\section{II.1. Antecedentes y evolución desde el inicio de la V República}

\section{II.1.1. Situación anterior a la reforma de 1962}

Inicialmente, hasta la reforma de 1962, la Constitución de 1958 establecía la elección del Presidente de la República por medio de un sistema indirecto, una especie de reclutamiento local, por medio de un colegio de electores, que combinaba la elección por parte de las asambleas parlamentarias, prevista en las Constituciones de 1875 y 1946 y la elección popular de la Constitución de $1948{ }^{29}$. Se establecia así un régimen parlamentario en el que, sin embargo, el fortalecimiento de los poderes del Presidente estaba en consonancia con la debilidad del Parlamento ${ }^{30}$. Pronto se vio la necesidad de corresponder a ese mayor poder presidencial, por comparación con la República anterior, con una mayor legitimidad, para cuya consecución no bastaba la ampliación del colegio de electores, sino que habia que descender a la fuente de la soberania, es decir, a la elección del Jefe del Estado por sufragio universal'31.

\section{II.1.2. Modo actual de provisión al cargo}

El artículo 6 de la Constitución francesa, en su redacción actual, dispone: «El Presidente de la República se elige por cinco años por medio de sufragio universal directo. Las modalidades de aplicación del presente artículo las fija una ley orgánican. Este artículo tiene dos partes indisociables, pero de importancia desigual, que pasamos a analizar.

29 Este colegio "ampliado" estaba compuesto por diputados y senadores (en cantidad inferior a un $1 \%$ ) consejeros generales y miembros de los consejos municipales (cuyo número variaba según la población del municipio) y representantes de los territorios de ultramar. El voto era obligatorio. Fue por este medio por el que se eligió al primer Presidente de la República.

30 La situación del Parlamento respecto del Ejecutivo en la Constitución de 1958 ha dado lugar a un parlamentarismo racionalizado.

31 Así lo manifestaba Léon Blum, al día siguiente de los discursos de Bayeux. Cfr. Giquel, Jean, "Article 6", en LuCHAIRE, François, y CONAC, Gérard, La Constitution de la République française, $2 .^{a}$ ed., París, Economica, 1987, pág. 333. 
Ya nos hemos referido a la reforma constitucional llevada a cabo por de Gaulle, por la que la elección del Presidente de la República pasó a realizarse por medio de sufragio universal directo ${ }^{32}$. En realidad es en esta reforma en la que descansa todo el sistema político de la V República ${ }^{33}$. La legitimidad que otorgaba la elección del Presidente por medio del sufragio universal y la aparición en ese mismo año del fenómeno mayoritario ${ }^{34}$, fenómeno que se prolongaría durante la década siguiente y que hizo que la mayoría parlamentaria coincidiera exactamente con la mayoría electoral, fomentaron una concepción presidencialista de la $V^{a}$ República, en la que el verdadero centro de poder era el Presidente, mientras que el Primer Ministro era un mero mandatario que, para gobernar, necesitaba la confianza de aquél, además de la de la Asamblea. La inversión de esta situación tras las elecciones legislativas de 1986, que dieron lugar a la primera diarquía o cohabitación y el resto de cohabitaciones que siguieron demostraron el carácter meramente coyuntural del llamado presidencialismo francés.

Según el artículo 7 de la Constitución, el sistema aplicado es el mayoritario (mayoría absoluta de los sufragios expresados). Si la mayoría absoluta no se consigue en la primera vuelta, se procede a

32 Ley constitucional $n .^{\circ} 62-1292$, de 6 de noviembre de 1962, que da forma a la revisión sometida a referéndum el 28 de octubre de 1962. Este referéndum, respondiendo a la concepción de Gaulle, llevaba implícita una cuestión de confianza, pero también implicaba un chantaje político-electoral. Así, de Gaulle afirmaba el 18 de octubre de ese año que se marcharía si la mayoría de "síes» expresados fuera débil, mediocre o aleatoria. Consiguió un $62,25 \%$ de votos afirmativos, que él interpretó como un apoyo suficiente. Esta misma idea de de Gaulle sobre el referéndum como revalidación de la confianza del pueblo motivó su dimisión con ocasión de referéndum de 1969 que pretendía reformar el Senado reduciéndolo a una mera cámara consultiva.

33 En efecto, la revisión de los artículos 6 y 7 de la Constitución sentaría las bases que permitirían a de Gaulle llevar a cabo su interpretación de la Constitución. Pero para Pierre AVRI la afirmación de que esta reforma supone el verdadero inicio de la $V$ República debe matizarse. Por lo tanto, hay que distinguir las consecuencias del referéndum, de la revisión y de las mismas elecciones legislativas de 1962.

34 El referéndum supuso una nueva alineación de las familias políticas de carácter bipolar: las que habian gobernado durante la IV República, partidarias del "no» y el resto. Según Pierre Avril (cfr. La Ve République. Histoire politique et constitutionnale, París, Presses Universitaires de France, 1987, pág. 73), se invierten en ese momento las reglas del juego existentes hasta la fecha, porque la lógica de las elecciones de representación, donde cada partido se esfuerza en conseguir votos según su ideología, fue sustituida por la lógica de las elecciones de decisión, en la que el punto central era el gobierno. 
una segunda vuelta, a la que sólo pueden presentarse los dos candidatos que hayan conseguido el mayor número de votos en la primera. La elección debe tener lugar entre los veinte días previos y los treinta y cinco posteriores a la finalización de los poderes del presidente en ejercicio. Este artículo también contiene disposiciones relativas a la vacancia $y$ al impedimento en el ejercicio de la presidencia, así como al fallecimiento o impedimento de los candidatos a la elección presidencial ${ }^{35}$.

11.1.3. Regularidad de las operaciones electorales, financiación de la campaña de los candidatos y transparencia financiera de la vida política

La presentación de candidaturas, la organización y regularidad de las operaciones electorales, así como la financiación estatal de las candidaturas se encuentran reguladas en la Ley 62-1292 de 6 de noviembre de 1962 y otras disposiciones posteriores que la modifican, todas ellas incorporadas al Código Electoral. El control de la regularidad de la elección presidencial se encuentra atribuido expresamente al Consejo constitucional por el artículo 58 de la Constitución ${ }^{36}$. Tras la LO 76-528, de 18 de junio, cada candidatura debe ir avalada por un minimo de quinientos ciudadanos, que deberán ser miembros del Parlamento, de los consejos regionales, "de la Asamblea de Córcega», de los consejos generales, del consejo de Paris, de las asambleas territoriales de los territorios de ultramar, de las Asambleas de Nueva-Caledonia, o bien por alcaldes o miembros elegidos del Consejo Superior de los franceses en el extranjero ${ }^{37}$. La Ley establece la entrega a cada

35 Cfr. Code constitutionnel commenté et annoté, op. cit., págs. 302 y ss.

36 Sobre este papel de control de la regularidad de la elección presidencial, consagrado en el artículo 58, cfr. comentarios a la decisión de 17 de mayo de 1969, Rec 78, RCJ V-1, en FAVOREU, Louis, y PHILIP, Loïc, Les grandes décisions du

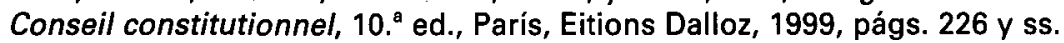

37 Antes de esta reforma, la LO n. ${ }^{\circ} 62-1292$ de 6 de noviembre y su reglamento de aplicación (aprobado por el decreto $n .^{\circ}$ 64-231 de 14 de marzo de 1964) establecía un sistema más permisivo, pues sólo exigía cien firmas recogidas entre miembros del Parlamento, del Consejo Económico y Social, consejeros generales y alcaldes elegidos (se excluian los alcaldes de los distritos de París). El sistema fue objeto de vivas críticas, porque su mayor permisividad motivó la inflación en el número de candidatos y la aparición de numerosos candidatos fantasmas. La citada reforma intentó paliar esto aumentando el número de firmas y la extensión geográfica de su reparto (cfr. GuCHET, Yves, La Ve République, 3. ${ }^{a}$ ed., París, Economica 1994, págs. 81 y ss.). 
candidato de un millón de francos por parte del Estado, a título de adelanto de la campaña, del que se devolverá la cantidad que no se haya gastado ${ }^{38}$. Asimismo, a cada candidato se le reembolsa una vigésima parte del límite máximo de gastos de campaña que le resulte aplicable, importe que se eleva a un cuarto de dicho límite para aquellos candidatos que en la primera vuelta hayan obtenido un $5 \%$ de los sufragios expresados, sin que esta cantidad pueda ser superior a la suma de los gastos reseñados por el candidato en su cuenta de campaña ${ }^{39}$.

La transparencia financiera de la vida política se encuentra regulada por dos leyes orgánicas de 1988, una aplicable al Presidente de la República y la otra a los miembros del Gobierno. La ya citada Ley orgánica $n .^{\circ} 88-226$ de 11 de marzo de 1988 -que remite en lo que al primero se refiere a la también citada Ley de 1962- obliga a los candidatos a presentar una declaración de su situación patrimonial y, en caso de elección, a presentar otra declaración antes de la finalización de su mandato, ya sea por expiración, ya por cese o dimisión.

\section{II.1.4. Elegibilidad}

La Ley 2000-295 de 5 de abril de 2000 dio una nueva redacción al artículo 44 del Código electoral (art. 1), en virtud de la cual, todo francés que tenga la calidad de elector puede presentarse como candidato y ser elegido, con reserva de los casos de incapacidad previstos por la ley ${ }^{40}$. Este artículo se aplica a todo tipo de elecciones. Sin embargo, en el caso de las elecciones presidenciales, la práctica ha revelado que en Francia existe una verdadera gerontocracia politica, pues los Presidentes han llegado a ese cargo ya bien alcanzada la madurez.

38 L. org. $n .{ }^{\circ} 90-383$, de 10 de mayo de 1990.

39 L. org. $n .^{\circ} 88-226$, de 11 de marzo de 1988.

40 Antes de esta reforma, el derecho de voto pasivo se adquiría a los veintitrés años de edad. Con la nueva ley, se equipararon los derechos de voto activo y pasivo. Esta equiparación se encuentra sin embargo restringida en el artículo 45 del mismo Código, en virtud del cual, nadie puede ser elegido si no justifica haber satisfecho las obligaciones legales sobre el servicio de las armas. Este cumplimiento de obligaciones para con el Ejército no impide que pueda presentarse como candidato un francés que haya obtenido una prorroga o esté desempeñando las obligaciones activas del servicio nacional (dfr. CC, 17 mayo 1969, Ducatel c/ Krivine, Rec 78, RCJ V-1, en FAVOREU, Louis, y PHILIP, Loïc, Les grandes décisions du Conseil constitutionnel, op. cit., idem). 
Sobre el acceso de las mujeres al mandato presidencial, cabe destacar la reforma constitucional llevada a cabo en 1999, que añadió un nuevo apartado al artículo 3 de la Constitución, en virtud del cual: La ley favorece el acceso igual de mujeres y hombres a los mandatos electorales $y$ a las funciones electivas ${ }^{41}$. A esta misma ley se debe el segundo apartado del artículo 4: [los partidos y los grupos políticos] contribuyen a la puesta en marcha del principio enunciado en el último apartado del artículo 3 en las condiciones previstas por la ley. La práctica en cambio no ha revelado aún el acceso de una mujer a la presidencia de Francia, pese a que, en estas elecciones, por ejemplo, ha habido cuatro candidaturas encarnadas por mujeres.

\section{II.1.5. Derecho de voto}

La condición general para ser elector, aplicáble a todas las elecciones francesas con sufragio universal directo de la República, es, según el apartado 4 del artículo 3 de la Constitución, tener la nacionalidad francesa y gozar de los derechos civiles y políticos. A estos requisitos debe añadirse la inscripción en la lista electoral, condición que deriva de la lógica de la operación electoral42. La inscripción en las listas electorales de los mayores de dieciocho años se realiza de oficio en virtud de la Ley 97-1027 de 10 de noviembre de 199743.

La Ley $n .^{\circ} 75-1329$ de 31 de diciembre de 1975 (arts. L. 71 a 78 y del Código electoral) instituyó la posibilidad del voto por poder para ciertos grupos de electores con determinados tipos de impedimentos

41 Nos referimos a la ley constitucional 99-569 de 8 de julio de 1999. Nótese que la utilización del término "favorecer» parece implicar una intervención positiva previa del legislador en esta cuestión y a la vez plantea el problema interpretativo de saber si se trata de una obligación de medios o de resultados. A nuestro juicio, en este último supuesto hubiera sido preferible el añadir el término "garantizar». En cualquier caso el Consejo Constitucional, en su decisión n. ${ }^{\circ} 2000-429$, DC de 30 de mayo de 2000 (JORF, pág. 8565), estimó que este apartado permitía al legislador dictar medidas bien incitativas, bien apremiantes (Cfr. Code constitutionnel commenté et annoté, op. cit., pág. 286).

42 Ídem, ibid., pág. 287.

43 Esta ley se encuentra recogida en el artículo 11-1 del Código electoral: "Sin perjuicio de la aplicación de las disposiciones del artículo L. 11, se inscriben de oficio en la lista electoral del municipio de su domicilio real las personas que cumplan la condición de edad después del último cierre definitivo de las listas electorales o que la cumplirán antes del próximo cierre definitivo de estas listas, siempre que cumplan las demás condiciones prescritas por la ley”. 
o discapacidades, en lugar del voto por correo. Esta disposición implica una derogación del principio del voto personal, justificada por la especial situación de las personas afectadas. Los decretos $n .^{\circ} 76-128$ de 6 de febrero de 1976, 76-158 de 12 de febrero de 1976 y 97-365 de 18 de abril de 1997 establecen las condiciones para votar por este medio (arts. $R * 72$ a $R{ }^{*} 80$ ). En relación con este punto, resulta ilustrativo señalar que el 21 de abril de 2002 se ha ensayó el voto electrónico en varios colegios electorales ${ }^{44}$.

\section{ANTECEDENTES Y PRECAMPAÑA ELECTORAL}

\section{III.1. Inversión del calendario electoral}

El saldo negativo del que el Partido socialista partía en las elecciones municipales arrojaba cierta incertidumbre sobre la oportunidad de la medida iniciada por el Gobierno con anterioridad a las citadas elecciones, consistente en anteponer las elecciones presidenciales a las legislativas, mediante la prolongación del mandato de la Asamblea Nacional. En efecto, la reducción del mandato presidencial de siete a cinco años motivaba que éstas tuvieran que celebrarse en primer lugar y con un estrecho margen temporal entre ambas ${ }^{45}$. En la exposición de motivos de las proposiciones de ley orgánica para modificar la fecha de expiración de poderes de la Asamblea Nacional ${ }^{46}$ se señalaban, como razones principales para anteponer los comicios presidenciales, la necesidad de respetar una cronología que hiciera de la elección presidencial el momento fuerte de la vida política y del cual dependieran las elecciones legislativas, advirtiendo que, de otro modo, la interferencia entre ambas campañas sería perjudicial para ambas funciones, legislativa y ejecutiva, poniendo como ejemplo que, de darse esa situación, un Primer Ministro salido de la nueva mayoría parlamentaria tendría que ser nombrado por un Presidente cuyo mandato estaría a pun-

44 Cfr. Le Monde, 24.04.02, pág. 28.

45 En cumplimiento de lo dispuesto en artículo 25 de la Constitución, el artículo 121 de la LO n. ${ }^{\circ} 85-688$, de 10 de julio de 1985, dispone: "Los poderes de la Asamblea nacional expiran el primer martes de abril del quinto año que sigue a su elección". A su vez, el artículo 122 de la misma LO dispone: "Salvo en caso de disolución las elecciones generales tienen lugar en los sesenta dias que preceden a la expiración de los poderes de la Asamblea Nacional"!.

46 Cfr. proposiciones de Ley orgánica números 2602, 2665, 2741, 2756, 1757 y 2773. 
to de finalizar. En definitiva, en las citadas propuestas se hacía hincapié en «asegurar la eficacia política del poder ejecutivo" $y$, dentro de éste, primar la función del Presidente como "clave de bóveda" del régimen francés de la $V$ República, gracias a la mayor legitimidad que implica la elección por sufragio universal directo, y se trataba por lo tanto de la posibilidad de una cohabitación ${ }^{47}$. Lo cierto es que, dentro del deseo del Gobierno - bien fundamentado jurídicamente- de invertir el calendario electoral podian adivinarse motivos de oportunidad política consistentes, principalmente, en evitar una derrota en las legislativas, si se cumplía la regla del castigo de los electores al partido de la mayoría. Asimismo anteponiendo las elecciones presidenciales, el Partido Socialista podría beneficiarse del desgaste del Presidente Chirac y tener más posibilidades de conseguir una victoria en dichas elecciones, tras lo cual, lo más probable sería que los electores ratificasen su elección en las legislativas, por la proximidad de ambas elecciones ${ }^{48}$. La proposición motivó el consiguiente rechazo de la derecha senatorial, que intentaria dilatar la adopción de la citada ley orgánica antes de las municipales, entorpeciendo reiteradamente su adopción. Finalmente, se siguió adelante con la inversión de calendario y la proposición fue adoptada por la Asamblea Nacional en abril y promulgada por el Presidente de la República en mayo de 200149. Paradójica-

47 En este artículo respetaremos el término periodístico de cohabitación (utilizado por primera vez por Pierre Avril en 1976, luego por Mitterrand en 1978, siendo Presidente Giscard d'Estaing, si bien su difusión definitiva se debió a Edouard Balladur, que lo utilizó en su artículo, aparecido en Le Monde, titulado "Ambivalence de la Constitution»), pese a que nos parece más riguroso, desde el punto de vista jurídico, el de diarquía, punto en el que seguimos a Pierre AvRIL (cfr. La V $V^{\theta}$ République. Histoire politique et constitutionnelle, Presses Universitaires de France, 1987, pág. 283). Según del Diccionario de Lengua Española (21. a ed., Madrid, Real Academia Española, 1992), diarquía es, no sólo el gobierno simultáneo de dos reyes, sino también la autoridad dividida y ejercida simultáneamente entre dos personas, dos instituciones o dos poderes, definición ésta que se ajusta perfectamente al fenómeno francés llamado cohabitación. Como apunta MarieAnne COHENDET (cfr. La cohabitation, leçons d'une expérience, Paris, Presses Universitaires de France, 1993, pág. 12), en los regímenes parlamentarios, la cohabitación -o diarquía - entre un Jefe de Estado y un Primer ministro sólo tiene lugar cuando la oposición al Presidente por parte de la Asamblea - a cuya confianza debe el Primer ministro su cargo - es absoluta.

48 Deciamos en nuestro artículo sobre las elecciones municipales de 2001 (op. cit., pág. 397) que la hipótesis contraria, la de una derrota del PS en las elecciones presidenciales, lo dejaría fuera de las legislativas. Esta afirmación debe matizarse a raiz de los resultados de las recientes elecciones.

49 El texto definitivo de esta Ley orgánica $n .^{\circ} 2001-419$ de 15 de mayo, el siguiente: "Art. $1 .^{\circ}$ El artículo LO 121 del código electoral queda así redactado: "Ar- 
mente veremos, al analizar los desconcertantes resultados de las pasadas elecciones presidenciales, que esta medida ha resultado poco efectiva en la práctica para descartar la posibilidad de una cohabitación.

\section{III.2. Desarrollo de los meses previos a la campaña electoral}

El final del año 2001 y los primeros meses del año 2002 se encuentran protagonizados por las causas judiciales y los escándalos relacionados con los dos partidos políticos más importantes, en especial los que afectan a la RPR, lo que se deja ver inicialmente en los son$\operatorname{deos}^{50}$, por lo que, en principio, parece que Jospin, tras cinco años de gobierno, parte en estos comicios presidenciales de una posición más ventajosa que Chirac, tras sus doce años de mandato presidencial, con el desgaste de opinión que ello implica ${ }^{51}$.

A principios de febrero los principales candidatos a la elección presidencial empiezan a esbozar sus programas electorales ${ }^{52}$ y a dar

tículo LO 121. - Los poderes de la Asamblea nacional expiran el tercer martes de junio del quinto año que sigue a su elección"». Por su parte, el artículo 2 dispone: "El artículo $10^{\circ}$ se aplica a la Asamblea nacional elegida en junio de 1997. La presente ley se ejecutará como ley del Estado".

50 Cfr. el sondeo Ipsos publicado en Le Monde el 2 de febrero y el sondeo Sofres publicado en la misma fecha en Le Figaro Magasin, en los que se observa un leve retroceso de Chirac (en torno al $46 \%$ ) y un aumento de Jospin, leve según el primero de los sondeos (alcanza un $51 \%$ ) y mayor según el segundo de los sondeos citados (alcanza un $60 \%$ ). En los meses previos a la campaña electoral, las dos fuerzas politicas principales intentan explotar al máximo cualquier tema que pueda perjudicar a su principal adversario político. Así, cabe citar el asunto financiero que implica al diputado europeo Jean-Charles Marchiani (RPR), la amenaza de regreso de Sto. Domingo, y posterior verificación del mismo, de Schuller, ex consejero general de los Hauts-de-Seine, relacionado con el escándalo de las viviendas de protección oficial, que había descrito a Le Monde el sistema de financiación de la RPR, o la aparición del libro del juez Halphen, sobre ese mismo tema, visperas de la fecha de la campaña electoral de Jospin. También puede citarse la investigación sobre las condiciones de compra de la casa de la pareja Jospin o el escándalo que afecta al Gobierno sobre la entrega de rehenes del Líbano (cfr. Ídem, ibid., 8 y 12).

51 En el mes de marzo tres jueces, símbolo de la lucha contra la corrupción, dejan la instrucción, reconociendo su impotencia para luchar contra la corrupción, y se van al sector privado (cfr. Le Monde, 14.03.02, pág. 12).

52 El 4 de febrero el PS lanza una campaña nacional sobre su proyecto 2002 "vida mejor, vida en unidad", con 500.000 ejemplares, que salen a la calle el 7 de marzo. En el ámbito nacional, los temas principales de que trata son la seguridad, la creación de una ciudadanía de residencia para aquellos extranjeros que no ten- 
su equipo a conocer. Jacques Chirac anuncia antes de lo previsto, el 11 de febrero en Avignon, su cuarta candidatura al Elíseo. Opone su pasión por todos los franceses a la ideologia del Primer ministro53, dando a entender que la elección presidencial es algo entre él lo el candidato) y el pueblo francés, o que en la elección presidencial el componente personal debe ser superior al ideológico. Al mismo tiempo defiende su gestión durante los cinco años pasados al frente de Elíseo, sobretodo en materia de empleo ${ }^{54}$. Paralelamente se repiten los ataques y reproches mutuos entre ambas fuerzas: la oposición critica al Gobierno la mala gestión en ciertos temas, como el de la vivienda ${ }^{55}$, o el de la seguridad.

El Partido socialista, por su parte, critica al del Presidente el abuso de la confianza depositada en él por los franceses ${ }^{56}$. En su precampaña aborda temas como el de la descentralización o el desarrollo racional y duradero. Hasta el final de la legislatura, el 22 de febrero, Jospin, situado a la cabeza de la "mayoría plural»57, utiliza la Asamblea como lugar para dar a conocer su política y replicar los ataques de la oposición ${ }^{58}$.

Pese a todo, se echa de menos una nítida línea divisoria entre los programas del partido del Gobierno, el Partido socialista, liderado por Jospin, y el de la oposición, la Reagrupación por la República o RPR, liderado por el Presidente Chirac, lo que denota la preocupación de ambas fuerzas por abarcar una franja lo más amplia posible de electores cercanos al centro. Estando como está Francia

gan derecho a votar en las elecciones municipales o el establecimiento de diversas medidas tendentes a profundizar en la democracia social. En el ámbito exterior destaca, en relación con la mundialización, la lucha contra los movimientos especulativos en el espíritu del uíndice Tobin» y la anulación de la deuda de los paises pobres (cfr. Le Monde, 3-4 de febrero de 2002, pág. 1,0 y 8 de febrero de 2002, pág. 7).

53 Le Monde, 13 de febrero de 2002, pág. 1.

54 ĺdem, ibid., pág. 8.

55 Cfr. Le Monde, 2 de febrero de 2002, pág. 8.

56 EL PS prepara pasquines titulados: "Derecha, abuso de confianza», refutando, punto por punto, el programa de la RPR (Cfr. Le Monde, 13.02.02, pág. 11). El Partido socialista acusa a Chirac de precipitar su candidatura para escapar de la justicia (ídem, ibid., pág. 8).

57 Esta denominación agrupa al PS, al PCF (Partido comunista francés), a los Verdes y a otros partidos de izquierda (Divers gauche).

58 Según Le Monde (21.02.02, pág. 1), durante la pasada legislatura hubo 186 respuestas del Primer ministro a cuestiones de los diputados, se adoptaron 220 leyes. 
en período de cohabitación y dado que los dos principales candidatos, Jospin y Chirac, representan a dos de las instituciones más importantes del Estado, sorprende ver a ambos colaborando y representado unitariamente a Francia, como en la cumbre de Barcelona, y al mismo tiempo enfrentados como candidatos rivales a la elección presidencial ${ }^{59}$.

\section{III.3. Precampaña electoral y situación de las fuerzas políticas más importantes}

Las notas más destacadas son:

III.3.1. Desunión de la izquierda plural, cada uno de cuyos partidos apoya a su candidato al Elíseo, dejando para la segunda vuelta la posibilidad de una llamada a la unión del voto de izquierda.

El 20 de febrero Jospin anuncia su candidatura como representante del Partido socialista ${ }^{60}$. En su primera intervención pública, el 21 de febrero, se declara socialista de inspiración, pero califica su proyecto de no socialista, lo que denota un viraje de su política hacia el centro. Entre sus compromisos figura la lucha contra el desempleo, la reforma de las pensiones y la modificación del estatuto penal del Presidente. Ataca a Chirac de incumplir las promesas dadas en 1995 e insiste en que el balance hay que realizarlo sobre la gestión del Presidente saliente, por tratarse de una elección presidencial, al tiempo que declara haber cumplido por su parte todos los objetivos del

59 En efecto, dado lo difuso de los limites entre ambas instituciones en período de cohabitación, en las circunstancias aludidas de precampaña y campaña electoral se crea una situación paradójica: si el Presidente defiende los logros conseguidos por el Gobierno, está poniendo medallas al Primer Ministro y facilitándole votos indirectamente; si, por el contrario, ataca directa y abiertamente su gestión, se encuentra en una situación impropia desde el punto de vista de la lnstitución que representa. El Gobierno, por su parte, responsable real de la marcha de la nación, no puede atacar la gestión del Presidente como cabeza visible del Ejecutivo, pues en situación de discordancia de mayorías los poderes de éste quedan reducidos a los de un Jefe de Estado parlamentario. Por lo tanto, los ataques deben ir dirigidos más a socavar su auctoritas. En este sentido resulta reveladora la profusión de escándalos que han rodeado a la RPR en estas elecciones.

60 Lo hace con una "carta a los franceses" enviada por fax a la Agencia France Press (cfr. Le Monde, 22.02.02, pág. 1). El 24 de febrero el Partido socialista lo inviste como candidato al Elíseo en un Congreso extraordinario. 
Gobierno, sobre todo en materia de empleo, consiguiendo invertir la curva del desempleo en los últimos cinco años. En materia de seguridad, uno de los temas que más se abordarán en estas elecciones, reconoce no haber conseguido logros importantes, si bien dice que no ha fallado la voluntad del Gobierno61. Condena implícitamente la cohabitación invitando al electorado a no renovar el voto a Chirac y a elegir la misma corriente o partido en ambos comicios, para que exista - dice - «un sentimiento de comprensión común y ganas de actuar en común" entre el más alto responsable del Estado y los ciudadanos $^{62}$.

Los socios del PS en la llamada izquierda plural son el PRG63, el $\mathrm{PCF}^{64}$, los Verdes y el MDC ${ }^{65}$. El arriba comentado viraje al centro del PS motiva que los puntos de desacuerdo con sus socios de la izquierda plural sean muy numerosos, lo que hace dudar a muchos diputados de la validez del acuerdo de 1997. Por ejemplo, el Partido comunista francés acusa al Partido socialista de desviarse a la derecha por su línea neoliberal y declara que no participará en un gobierno de centro-izquierda66. De todos modos el peso específico de este partido en el seno de la izquierda plural, a la que se sumó en 1995, ha ido disminuyendo progresivamente desde 1997, por la fuga de votantes a otros partidos de extrema izquierda. Los Verdes, por su parte, afirman que no se dan las condiciones para un acuerdo con el Partido socialista, porque los logros conseguidos por el PS están muy lejos de lo que ellos consideran mínimos en diversos temas, especialmente en materia nuclear - tema que provoca vivas tensiones entre ambos partidos-, social y de transportes, y por lo tanto no justifican en ningún caso un contrato con el PS, sino a lo sumo cierto entendimiento electoral para las legislativas - que para este partido es objetivo prioritario respecto de las presidenciales - entendimiento que no

61 Cfr. Le Monde, 23 de febrero de 2003, pág. 6.

62 Cfr. ídem, ibid., pág. 8. En contraste con esta opinión, defendida por el Gobierno saliente, Bernard Roman, Presidente de la Comisión de leyes de la Asamblea, denuncia que el Gobierno "no ha podido, o no ha querido, realizar ciertas reformas hasta el final", de lo cual se lamenta (cfr. ídem, 19.02.02, pág. 6).

63 Partido Radical de Izquierda.

64 Partido Comunista Francés.

65 Movimiento de los Ciudadanos.

66 Cfr. Le Monde, 20.02.2002, pág. 7. Temas de discordia entre el PCF y el PS son, por ejemplo, el de las jubilaciones, el futuro de los servicios públicos y el pacto de la estabilidad presupuestaria europea, que desea ver reemplazado por un pacto de progreso social (cfr. Le Monde, 26.03.02, pág. 9). 
obstante no se haría a cualquier precio67. EI PRG ${ }^{68}$ también presenta una candidata a estas elecciones, Mme. Taubira, que no se retira pese a figurar muy por debajo de los otros socios de la izquierda plural en los sondeos ${ }^{69}$. Con el MDC, creado por Jean-Pierre Chèvenement, el principal punto de discordia es el relativo al estatuto de Córcega, tema por el que dimitió de su cargo como Ministro del Interior del gobierno Jospin. Chevènement defiende la indivisibilidad de la República ${ }^{70}$. Intenta progresar tanto en el electorado de izquierdas como en el de centro-derecha ${ }^{71}$. Su posible abanico de electores va desde la extrema izquierda trotskista a la derecha soberanista, pasando por radicales y antiguos gaullistas. Inicia la precampaña bien situado como para ocupar el puesto de tercer hombre, capaz de decidir, con su consigna de voto a su electorado para la segunda vuelta, el resultado de las elecciones.

III.3.2. La derecha conservadora, que inicia su precampaña con una imagen de perdedora, motivada principalmente por la amenaza de Schuller, pero también por los poco rotundos resultados de los anteriores comicios municipales, se une en torno al Presidente, bajo la fórmula «la Unión en Movimiento», expresión que se remonta al 4 abril de 2001, vísperas de las elecciones municipales ${ }^{72}$. La UEM, concebida inicialmente como un instrumento de renovación de la oposición, es de hecho una agrupación que busca la reelección de Jacques Chirac, y convertirse en ese caso en el partido del Presidente ${ }^{73}$.

67 Ver declaraciones de Dominique VoYNET, Le Monde, 17-18 de febrero de 2002, pág. 6, y 20.02.02, pág. 8. En efecto, dentro de los Verdes está, por un lado, una minoría partidaria de la ruptura - ven deshonroso un acuerdo con el PS - y los partidarios del entendimiento, línea defendida por Dominique Voynet - prefieren apoyar al PS en una segunda vuelta que ver ganar a la derecha-, línea que ha ratificado finalmente la Asamblea general. Sobre los distintos puntos de desacuerdo de los Verdes con el PS, cfr. Le Monde, 27.03.02, págs. 7 y 10.

68 Partido Radical de Izquierdas.

69 Cfr. Le Monde, 13.03.02, pág. 10.

70 Personalidades de la UDF no descartan la unión en la segunda vuelta con Chevènement (cfr. 7.02.02, págs. 1,8 y 9 ).

71 El perfil de sus votantes lo constituyen los mayores de sesenta y cinco años, los habitantes de las grandes ciudades, las personas con altos ingresos y los estudiantes de secundaria (cfr. Le Monde, 07.02.02, pág. 8).

72 En esta fecha 1.500 electos de la oposición respondieron al Hamamiento por la "alternancia 2002 ", asociación creada tres meses antes por tres diputados: Renaud Dutreil (UDF), Hervé Gaynard (RPR) y Dominque Bussereau (DL).

73 La primera convención nacional de esta agrupación tiene lugar en Toulouse, el 23 de febrero de 2002. 
Reúne, además de a los chiraquíes en línea directa, a antiguos partidarios de d'Estaing, Balladour, y a miembros de la task force de Alain Juppé. El resultado es, por lo tanto, una aproximación a posiciones de centro también por parte de la derecha tradicional.

III.3.3. En cambio a la UEM no se suman los principales candidatos de centro-derecha, al tiempo que, también dentro de sus correspondientes formaciones, existe desunión, dado que muchos de sus militantes se adhieren a la formación presidencial. La UDF74 presenta a su candidato François Bayrou, que en vísperas de las municipales del año 2001 tomó el testigo de Raymond Barre. Tanto el candidato como las nuevas generaciones de este partido se oponen a la creación de un "partido del Presidente". Pese a ello se produce una emigración hacia esta agrupación de líderes de la UDF, en parte movidos por los malos resultados que los sondeos le auguran al candidato de la UDF. El candidato Bayrou, por su parte, se declara partidario de la pluralidad de la derecha para ganar a la izquierda y de atraer a electores con esa distinta visión, para luego llamar a votar por Chirac en la segunda vuelta ${ }^{75}$.

El otro principal partido de centro liberal, Democracia Liberal (DL), también presenta a su propio candidato, Alain Madelin, que rechaza, al igual que Bayrou, sumarse a la UEM, al tiempo que denuncia el giro al centro de ambos jefes del Ejecutivo como una consecuencia de la cohabitación, que frena la adopción de reformas $^{76}$. Cree en la unión de la derecha para ganar, pero no cree que ello sea posible con el programa actual defendido por Chirac. Los sondeos le pronostican unos resultados parecidos a los de Bayrou.

III.3.4. La extrema izquierda, que también está desunida, ha ido ganando los votos de los electores de izquierdas desengañados del PCF y del PS, acusando a éste de practicar una política de dere-

74 Cfr. Le Monde, 21.02.02. Bayrou cesa a todos aquellos que no apoyarian su candidatura a las presidenciales.

75 "Si abandono - dice-, significará la muerte de esta familia política" (cfr. Le Monde, 27 de febrero de 2002). Exige a cambio utratamiento de socio y respeto" en el seno de la nueva mayoría (cfr. Le Monde, 26.02.2002).

76 Refiriéndose a los mismos, critica su actuación con estas palabras: "No sólo han disuelto la Asamblea Nacional, también han disuelto las ideas" (cfr. Le Monde, 28 de febrero de 2002, pág. 9). 
chas y a aquél de pactar con el gobierno. El principal competidor de aquéllos es $\mathrm{LO}^{77}$, liderado por Arlette Laguiller, que se presenta por quinta vez a unas elecciones presidenciales y que reivindica siete mil quinientos militantes. Desde 1995 puede situarse entre los movimientos antimundialización. Laguiller propone la creación de un "gran partido de extrema izquierda" tras las elecciones presidenciales $^{78}$.

Otro partido de extrema izquierda que ha ido ganando fuerza en los últimos comicios es el Partido de los Trabajadores (PT), formación trotskista fundada por Pierre Lambert, cuyo candidato a estas presidenciales es Daniel Gluckstein.

III.3.5. La extrema derecha sigue dividida en su carrera hacia estas elecciones, entre el FN ${ }^{79}$, liderado por Jean-Marie Le Pen, que en las municipales de 2001 sorprendió con unos resultados, aunque inferiores a los de 1995, muy superiores a los que le auguraban los sondeos, y el MNR, de Bruno Mégret, cuya idea es utilizar tanto estas elecciones como las legislativas inmediatamente posteriores para situarse, pues no se ve en la segunda vuelta ${ }^{80}$. Le Pen, que intenta aparecer al inicio de la campaña como un hombre de derecha moderada, pero pronto radicaliza su discurso aún más si cabe ${ }^{81}$.

III.3.6. La existencia de muchos otros partidos cuyo objetivo no es ganar las elecciones, sino darse a conocer y hacerse escuchar como grupos de presión. En este sentido, la prensa nacional califica de excepcional la labor desarrollada por Jean-Saint-Josse, de $\mathrm{CPNT}^{82}$, que se presenta como un candidato de la Francia rural. Su eslogan es «la Francia de las diferencias, de las minorías, de los colores". No se trata, por lo tanto, de un partido con una ideología de tipo político, sino más bien cultural o incluso social. Prueba de ello es que su potencial electorado procede de corrientes políticas muy diversas: extrema derecha, centro, izquierda social o izquierda comunista.

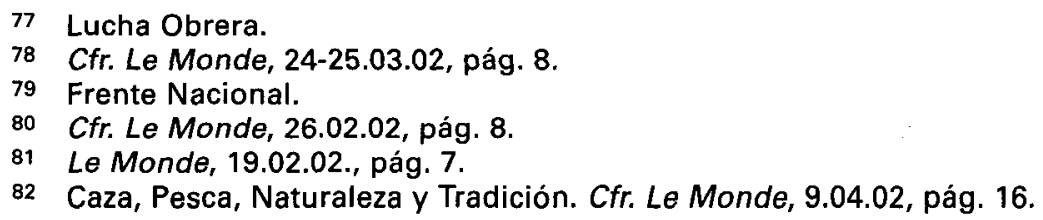




\section{CAMPAÑA ELECTORAL}

La campaña, iniciada el oficialmente el $\mathbf{5}$ de abril, se caracteriza por las siguientes notas:

\section{IV.1. Candidatos}

El Consejo Constitucional valida finalmente dieciséis candidaturas a la elección presidencial, con lo que se bate el récord de 1974, en el que se presentaron doce. Cinco de los candidatos que ahora se presentan ya concurrieron a las elecciones de $1995^{83}$.

\section{BRUNO MEGRET (MNR) 84}

Quiere reconstruir su idea de la "verdadera derecha" y llevarla al poder como en Italia y Portugal. Los sondeos le pronostican unos resultados muy inferiores a los de Le Pen (sólo un 3\%, mientras que en las europeas obtuvo sólo un $3,29 \%)^{85}$, del que se escindió y que constituye su principal competidor político ${ }^{86}$.

\section{CHRISTIANE TAUBIRA (PRG)}

Esta candidata, de etnia antillana, líder del movimiento radical de izquierda (Partido Radical de Izquierda), defiende, por un lado, la equiparación de los extranjeros del antiguo imperio colonial a los extranjeros europeos $y$, por otro, la igualdad entre los franceses, sea cual sea su etnia. Se siente de izquierdas pero no ha sido militante; su eslogan es: «Francia plural, Francia fraternal»87. Se la ha calificado como la "Pasionaria de los DOM, TOM y de las barriadas ${ }^{88}$. Como can-

83 Estos candidatos que reinciden son: Jacques Chirac (RPR), Lionel Jospin (PSF), Jean-Marie le Pen (FN), Robert Hue (PCF) y Arlette Laguiller (LO).

84 Movimiento Nacional Republicano.

85 Cfr. Le Monde, 18.04.02.

86 En efecto, sabe que su principal cantera de votos está entre los que eligen a Le Pen e intenta, por consiguiente, desanimar a éste electorado de votar al dirigente del FN (cfr. Le Monde, 21.02.02, pág. 8).

87 Cfr. Le Monde, 26.03.02, pág. 10.

88 DOM (Departamentos de Ultramar); TOM (Territorios de Ultramar). Sobre la calificación apuntada, cfr. Le Monde, 27.03.02., pág. 8). 
didata de izquierdas, pide el voto útil para Jospin para la segunda vuelta, para evitar que gane la derecha ${ }^{89}$.

\section{CHRISTINE BOUTIN (Forum des Républicains Sociaux)}

Lidera un partido de confesión católica que persigue la recuperación de los valores tradicionales, haciendo especial hincapié en lo social. Sus temas principales son el respeto al valor de la vida, por lo que está en contra del aborto y la defensa de la familia ${ }^{90}$.

\section{CORINNE LEPAGE (CAP-21)}

La diferencia fundamental de esta ecologista con el resto de candidatos es, aparte de defender ideas ecologistas, el estar a favor de una transferencia importante de competencias de los municipios a las aglomeraciones urbanas, mientras que el resto de candidatos no desean debilitar el poder de los municipios ni cambiar el sistema local ${ }^{91}$.

\section{DANIEL GLUCKSTEIN (PT)}

Lidera el Partido de los Trabajadores. Es trotskista y lambertista. Su eslogan es reconquistar la democracia, pero no en estas elecciones que él tilda de «mascarada». Defiende el debate de las ideas y la acción militante ${ }^{92}$. Ha realizado una buena campaña entre los alcaldes y elegidos rurales (lo que le ha facilitado considerablemente la obtención de las firmas necesarias para depositar su candidatura) centrada, no en el candidato, sino en la necesidad de salvar la democracia municipal y denunciar la intermunicipalidad, así como la Ley Chevènement de 1999. En este aspecto su tesis es opuesta a la Corinne Lepage (CAP-3).

\section{FRANÇOIS BAYROU (UDF)}

Es diputado europeo. Sustituyó a Raymond Barre en la presidencia del partido. Su objetivo al inicio de la precampaña era el de ser el "tercer hombre" de estas elecciones, prepararse para la próxima cita presidencial de 2007 y acercarse lo máximo posible al $9,3 \%$

89 Cfr. 17.04.02., pág. 9.

90 Cfr. Le Monde, 19.04.02.

91 Cfr. Le Monde, 06.04.02,p. 13.

92 Cfr. Le Monde, 19.04.02, pág. 16. 
obtenido en las europeas de 1999, evitando siempre caer por debajo del $5 \%^{93}$.

\section{JACQUES CHIRAC (RPR)}

Este ya dinosaurio de la política presenta su quinta candidatura al Elíseo. En esta campaña evita proclamarse de derechas diciendo que "desconfia de las etiquetas»94. Tiene presente que a su defensa de la "etiqueta liberal» durante el primer período de cohabitación, siguió su derrota en las presidenciales y posteriores legislativas de 1988. A partir de entonces suprimió las referencias al liberalismo económico, pese a que muchos de los diputados que lo apoyaban en la Asamblea aspiraban a la puesta en práctica de un programa económico mucho más vigoroso ${ }^{95}$. En este sentido es, de los cinco candidatos que repiten candidatura en estas elecciones, el único que ha cambiado la línea de su discurso. Ahora intenta defender el balance de su gestión al frente del Elíseo y, por lo tanto, ha desaparecido del mismo la fractura social96.

Su estrategia en esta campaña es no dar pasos en falso, para no perder votos, dado que los sondeos le auguran la victoria en estas elecciones. Por lo tanto, prefiere concentrarse en la segunda vuelta. Mientras, su Jefe de Gabinete intenta evitar cualquier interrogatorio judicial, para no perjudicar el resultado de las elecciones ${ }^{97}$.

\section{J. M. LE PEN (FN)}

Confía en que la erosión de Jospin, augurada por los sondeos, y el debilitamiento de Chirac le favorezcan en la segunda vuelta. Su objetivo es sobrepasar el $15 \%$ obtenido en las elecciones presidenciales de $1995^{98}$. Se ha beneficiado de los discursos sobre seguridad

93 En estos objetivos pesa el hecho de que en 1988 Raymond Barre reunió en su nombre el $16,54 \%$ de los votos. Cfr. Le Monde, 19.04.02.

94 Cfr. Le Monde, 26.03.2002, pág. 8.

95 Un ejemplo de esto se dio cuando defendió su programa económico tuvo mucho cuidado de que no se confundiera con el de la organización patronal Medef, como aspiraban muchos de sus lugartenientes (cfr. Le Monde, 26.03.02, pág. 8).

96 En efecto, en 1995 decía «Francia va mal. Hemos llegado a pensar que no teníamos prisa por nada. Ahora bien, yo he venido a decirles a los franceses que hay que renunciar a la renuncia» (cfr. Le Monde, 11.04.02, pág. 10).

97 Cfr. Le Monde, 10.04.02, pág. 8.

98 Un sondeo IFOP realizado en abril le atribuye un $13 \%$ de intención de voto (cfr. Le Monde, 11.04.02, pág. 10). 
de los otros candidatos, al tiempo que ha explotado una posición de "víctima" denunciando maniobras políticas por parte de la RPR para impedir que consiguiera las quinientas firmas necesarias para validar su candidatura ante el Consejo constitucional ${ }^{99}$.

\section{JEAN PIERRE CHEVENEMENT (PR) ${ }^{100}$}

Al presentarse como el "tercer hombre» en esta campaña se ha propuesto un objetivo muy ambicioso (los sondeos realizados le auguran un porcentaje de votos de entre el 6 y el $8 \%$ ), pero también ha asumido un riesgo, pues no conseguirá ese papel de candidato "bisagra" como menos de un 9 o un $10 \%$ de los sufragios ${ }^{101}$. Evita decidirse de cara a la segunda vuelta (ni por Jospin o ni por Chirac), pese a que sus allegados le animan a hacer una fuerte llamada al electorado republicano y salir de su ambigüedad en la segunda vuelta ${ }^{102}$. Intenta presentarse como un hombre de centro ${ }^{103}$. Su idea central es que la ley sea la misma en Córcega y en Francia. Por lo que respecta a Europa, desea una reforma en la que la iniciativa la compartan la Comisión y el Consejo y propugna la publicidad de los votos en el Consejo. Sus allegados piensan que debería hacer una fuerte llamada al electorado republicano de derechas.

\section{JEAN SAINT-JOSSE (CPNT)}

Candidato a las presidenciales por el partido «Caza, pesca, naturaleza y tradiciones", desea alargar su base electoral, dirigiéndose, no sólo a los cazadores, sino al conjunto del mundo rural y defendiendo en especial una mayor dotación de servicios públicos en los municipios pequeños.

Dispone de una implantación geográfica estable: las zonas del sudoeste, mediodia, norte, Picardie y Baja Normandía son sus principales bastiones desde 1989. En las europeas de 1999 obtuvo un $16,10 \%$ de los votos, de modo que calificaría de fracaso cualquier resultado por

99 En efecto, si Le Pen no saliera candidato, los votos de derechas irían a Christine Boutin y a Alain Madelin para desembocar en la segunda vuelta en Chirac.

100 Pôle Républicain.

101 Cfr. Le Monde, 19,04.02.

102 Cfr. Le Monde, 06.03.02, pág. 8.

103 En un mitin en Paris se centra en lo que él denomina ulas tres grandes causas nacionales" o las tres revoluciones legales: "la Francia reencontrada", la ciudadanía cualificada (rélévée) y el "trabajo revalorizado" (cfr. Le Monde, 07.03.02, pág. 9). 
debajo de dicha cifra. El perfil de su electorado es joven $y$ de clase obrera. Su objetivo es captar votantes de la derecha en las presidenciales y arrebatarle muchos de sus escaños en las legislativas, razón por la que Chirac intenta con él un acercamiento.

\section{LIONEL JOSPIN (PS)}

Primer ministro desde las elecciones legislativas que siguieron a la disolución de la Asamblea Nacional por Jacques Chirac en 1997, lo que dio lugar a una nueva cohabitación que se prologaría hasta esta doble cita electoral de 2002, se presenta por segunda vez al Elíseo. En las elecciones presidenciales de 1995 relanzó las ideas de Jacques Delors sobre la Unión europea, a saber: la creación de una moneda única, un programa único para crear empleo, una política comercial europea y un ejército europeo. También está en el origen de la reforma sobre la reducción del mandato presidencial de siete a cinco años ${ }^{104}$. Su mandato como Primer ministro se ha caracterizado por la adopción de medidas relacionadas con lo social. Su evolución política personal ha basculado desde los orígenes trotskistas a una posición muy cercana al centro, periodo durante el cual ha cometido algunos errores político ideológicos importantes, como el elogio que el 12 de noviembre de 1997 hizo del comunismo francés, tras la aparición del «libro negro" del comunismo o la acusación de irresponsabilidad a los que apoyaban a los emigrantes "sin papeles» ${ }^{105}$. En su campaña, redactada por el "ala moderna" del PS, practica un socialismo moderado. Desea restaurar el espíritu de responsabilidad para «presidir de otra forma" y para ello adopta cinco iniciativas: «quiero una Francia activa, segura, justa, moderna y fuerten, declara, al tiempo que reconoce que en su caso el poder no le ha distanciado, sino acercado a los franceses. En realidad, la desviación de su programa al centro (dejando atrás su pasado trotskista y después mitterrandista), sin ninguna propuesta verdaderamente rompedora da la impresión de que su discurso se está volviendo demagógico ${ }^{106}$.

Su estrategia en esta campaña es intentar movilizar a su electorado desde la primera vuelta, cuyo perfil es, según los sondeos, más joven que el de Chirac.

104 Cfr. Golg MARTINEZ, Juan Manuel, «Las elecciones presidenciales de 1995 en Francia", en Revista de Derecho Político, n. ${ }^{\circ}$ 41, Madrid, UNED, 1996, pág. 320.

105 Cfr. supra, "Mi proyecto es socialista". También cfr. Le Monde, 19.02.02, pág. 6 .

${ }_{106}$ Cfr. Le Monde, 22.02.02, pág. 1, y 13.03.02, pág. 19. 


\section{NOËL MAMÈRE (LES VERTS)}

Su objetivo en esta campaña es no bajar del $5 \%$ de los votos, para conseguir un mejor apoyo financiero, si bien es consciente de que dicho objetivo no les daria la posición que necesitan en el paisaje politico de estas elecciones.

\section{ROBERT HUE (PCF)}

Este candidato se enfrenta a la peor situación histórica del Partido comunista francés en una elección presidencial. Su objetivo en estas elecciones será limitar al máximo los desgastes y conseguir una puntuación baja, pero aceptable, sin acercarse demasiado a la barrera del $5 \%$.

\section{ALAIN MADELIN (DL)}

Es diputado europeo. Se presenta por su cuenta, tras haber sido una de las "claves obreras» de la campaña de Chirac. Se proclama asimismo líder en Francia de una corriente liberal del estilo de la que están concibiendo en Europa Aznar, Blair y Berlusconi, que buscan hacer de Europa una de las zonas más competitivas del mundo ${ }^{107}$. En estas elecciones, tras dudar en un posible contrato con la RPR para no defraudar a sus electores, se esforzará posteriormente en llevar a cabo el mismo anunciando un posible acuerdo con la RPR de cara a la segunda vuelta ${ }^{108}$. Sus propuestas son las que más satisfacen a la organización patronal ${ }^{109}$, al tiempo que Chirac intenta alejarse el máximo de las demandas patronales.

\section{ARLETTE LAGUILLER (LO)}

Veterana en las elecciones presidenciales, a las que se presentó por primera vez en 1974 -ésta es su quinta candidatura-, en un libro publicado recientemente intenta omitir cualquier referencia a su pasada afinidad trotskista. Defendiendo proposiciones honradas y tradicionales de izquierdas como la prohibición de los despidos o el levantamiento del secreto bancario de las grandes empresas, y presentándose como una especie de "santa del pue-

107 Cfr. Le Monde, 19.02.02, pág. 7.

108 Cfr. Le Monde, 19.04.02.

109 Los puntos de coincidencia versar, entre otros temas, sobre la jornada laboral (de treinta y cinco horas), la tributación, las jubilaciones, la sanidad $y$ el seguro de enfermedad (cfr. Le Monde, 26.03.02, pág. 8). 
blo" ${ }^{110}$, ha acaparado gran parte de los votos de izquierda del PCF. Declara que no dará consigna de voto para la segunda vuelta111 - lo que es vivamente criticado por el líder del PCF, Hue, por conducir a la inutilidad de su voto y por Jospin, que afirma que sólo con un gobierno de izquierdas se podrá dar respuestas a los problemas de empleo, jubilaciones y salud - pero apela a la unión del mundo del trabajo ${ }^{112}$. Su mayor lucha estriba en combatir los despidos colectivos, tema en el que, según ella, el Gobierno ha fracasado reiteradamente en sus cinco años de gestión, y en reformar el sistema de jubilaciones. Su objetivo es financiarlas mediante el pleno empleo.

\section{OLIVIER BESANCENOT (LCR)}

Su formación no había intentado presentarse a unas elecciones presidenciales desde 1974. Es de un radicalismo puro. Este candidato propugna la prohibición total de acumular mandatos electorales, la supresión del Senado, la reestructuración del sistema fiscal (particularmente injusto por el IVA), la erradicación de los paraisos fiscales, la defensa del sector público, la prohibición de los despidos en las empresas con beneficios o, incluso, la nacionalización de la industria farmacéutica ${ }^{113}$. Su objetivo en esta campaña es darse a conocer y no dejar que LO se haga con el monopolio del voto de la extrema izquierda. Su posición respecto al PS no es tan rotunda como la de Laguiller: hay una gran diferencia entre la RPR y el PS, aunque no pediría el voto para Jospin en la segunda vuelta114.

\section{IV.2. Temas electorales}

Los candidatos ya veteranos en este tipo de comicios han guardado la línea de su discurso, a excepción de Jacques Chirac, que, en

110 Le Monde, 14.03.02, pág. 8. Cuenta además con la auctoritas que le proporciona Marc Pechanski, especialista mundialmente conocido por su trabajo en la descodificación del genoma humano y que desde hace treinta y cinco años está comprometido con LO (cfr. ídem, id.).

111. Declara que, desde 1988 su partido ha intentado acabar con el chantaje de un gobierno de izquierdas que, apoyado por otros partidos de izquierdas para evitar que ganara la derecha, hacía una política de derechas (cfr. Le Monde, 26.03.02, pág. 10).

112 Cfr. Le Monde, 17.03.02, pág. 7.

113 Cfr. Le Monde, 11.04.02.

114 Cfr. Le Monde, 19.04.02. 
lugar de denunciar el errado camino de Francia, como hacia cuando aspiraba a la presidencia de la República, se acomoda y defiende el balance de su gestión al frente del Elíseo, haciendo suyas, por lo demás, posiciones defendidas por el PS, con lo que se observa una centralización de los principales contendientes en estos comicios ${ }^{115}$. Se observa una línea divisoria en los temas electorales, a un lado de la cual, se pueden situar los que afectan directamente a los ciudadanos (seguridad, empleo, pensiones, fiscalidad, familia, educación, etc.) y, a otro, los más propiamente relacionados con la organización del Estado, la Unión Europea o el resto del mundo (estatuto del Presidente, reforma del Senado, descentralización, estatuto de Córcega, el papel de los gobiernos de los Estados miembros de la Unión en la UE o la mundialización). Lo más destacable en el tratamiento de los temas de campaña es la gran similitud entre los programas de los principales candidatos. Seguidamente pasamos a analizar los más importantes.

\section{IV.2.1. Seguridad ciudadana}

Este tema domina la campaña. Lo tratan todos los candidatos, pero sobre todo Chirac ${ }^{116}$, Jospin, Chevènement ${ }^{117}$ y el ultraderechis-

115 A la ausencia de radicalismo y al centrismo del Partido socialista ya nos hemos referido supra (cfr. pág. 25).

116 Ya antes de la campaña Chirac se refiere a la inseguridad con estas palabras: "La violencia está cambiando el rostro de nuestra República..., crea el miedo... y la situación va a peor». Defiende la «impunidad cero» (que ninguna infracción quede sin respuesta y que además ésta sea proporcional, inmediata y disuasiva). Para ello promete la creación de un Ministerio de seguridad interior bajo la presidencia del Jefe del Estado, que reunirá regularmente al Primer Ministro, a los ministros afectados y a altos responsables de seguridad, así como a los Consejos locales de seguridad, bajo la autoridad del alcalde o presidente de la aglomeración. Desde el punto de vista judicial y penal aspira al tratamiento de las denuncias en tiempo real, a una "justicia de proximidad", asi como a la creación de centros preventivos cerrados para el ingreso provisional de los menores en espera de juicio. En el nivel familiar y educativo propugna la asistencia a la familia para un mejor desempeño de su tarea educativa y la creación en los centros de educación de "planes de seguridad» destinados a evitar el absentismo escolar. En el terreno urbanístico prevé relanzar una política de "zonas francas" y una nueva política de vivienda encaminada a favorecer la desconcentración urbanística (cfr. Le Monde, 20.02.02, págs. 1 y 8 ).

117 Jospin y Chevènement acusan a Chirac de plagio en este tema. Jospin dice que el Gobierno ya estaba trabajando en lo que Chirac ahora propone. La ace- 
ta Le Pen, que hace de este tema el centro de su campaña. A finales de febrero se anima a Chirac a reforzar su línea de discurso en este tema, dejando el resto de asuntos en un segundo plano'118. En la izquierda, sólo los Verdes y la LCR se muestran hostiles a tratarlo. El PCF y LO no se pronuncian ${ }^{119}$. En realidad, este protagonismo dado por los candidatos al tema de la seguridad favorece a Le Pen, que ha hecho de este tema, utilizando un discurso populista y xenófobo, el centro de su campaña electoral.

\section{IV.2.2. Empleo}

El tema del empleo sigue al de la seguridad a larga distancia. El objetivo es acabar con el desempleo. El Gobierno reivindica, como uno de sus grandes logros, la jornada de treinta y cinco horas, ya bien implantada y con muy buena aceptación entre el electorado más joven. Esta ley es contestada por la derecha que, sin embargo, no se atreve a preconizar su abrogación sino, a lo sumo, la revisión de su aplicación. Desea, al igual que Chevènement, mayor flexibilidad en su puesta en práctica. Esta última también es contestada, por motivos distintos, por el PCF, los Verdes y la extrema izquierda ${ }^{120}$.

\section{IV.2.3. Fiscalidad}

Es otro de los temas en los que compiten los principales contendientes políticos de estos comicios. Existen pocas diferencias entre

lerada entrada de éste en campaña, presentando como suyas ideas del Gobierno, de las cuales tenía conocimiento por razón de su cargo, es calificado por aquellos candidatos de deslealtad. Chevènement, aludiendo a las numerosas causas judiciales que rodean a la RPR, dice que lo correcto sería aplicarla en todos los niveles (cfr. Le Monde, 21.02.02, pág. 7). El Elíseo responde a estas acusaciones diciendo que la proclamación de Jospin de su deseo de una Francia segura, activa, justa, moderna y fuerte implica un reconocimiento de la mala gestión del Gobierno hasta la fecha en el tema de la seguridad (cfr. ídem, 22.02.02, pág. 7). Chevènement propone acabar con la delincuencia juvenil reforzando la autoridad de los maestros (cfr. Le Monde, 23-24.03.92).

118 Cfr. Le Monde, 27.02.02. En efecto, así lo hará durante todo el mes de marzo, centrándose en la lucha contra la inseguridad y dejando el desempleo en segundo lugar (cfr. Le Monde, 7, 15 y 23 de marzo de 2002).

119 Cfr. Le Monde, 23.03.2002.

120 Cfr. Le Monde, 28.02.02, págs. 1 y 7. 
ellos. A pesar del menor crecimiento económico y del remonte del déficit público en $20011^{121}$, la generalmente sana situación de las finanzas públicas francesas permite que los programas de los grandes candidatos a la elección presidencial resulten financieramente posibles. La real diferencia entre ellos está en el margen de actuación que permiten, dado que cuanto más se bajen los impuestos, menos podrán aumentarse los gastos ${ }^{122}$.

Chirac realiza una propuesta espectacular anunciando una bajada del impuesto sobre la renta de un tercio en el plazo de cinco años $y$ de un $5 \%$ ya desde $2002^{123}$. Al mismo tiempo promete reforzar los servicios públicos, algo que en principio parece contradictorio, pues promete la bajada de impuestos, pero manteniendo las cargas públicas, o la disminución de las cargas sociales sin interrogarse sobre la financiación de la seguridad social ${ }^{124}$.

\section{IV.2.4. Pensiones}

La reforma de las pensiones figura en los programas electorales de todos los candidatos ${ }^{125}$. En realidad las posiciones de los dos principales candidatos no son demasiado dispares. Chirac reprocha al

121 Cfr. Le Monde, 14.03.02. Este aumento del déficit público en 2001 obedece al crecimiento constante de los gastos públicos (debido en especial la remuneración de los funcionarios) y a una progresión ralentizada de los ingresos.

122 En este sentido, el proyecto financiero más costoso es el de Chirac de 30.000 millones de euros, frente al de Jospin, de 18.000 millones de euros (cfr. Le Monde, 09.03.02).

123 Cfr. Le Monde, 01.03.02, págs. 1 y 8, y 17.04.02, pág. 1. El discurso de Chirac en este punto es típicamente de derechas. Conforme avanza la campaña retira de su programa la reducción del impuesto sobre sociedades (cfr. Le Monde, 24 y 25 de marzo de 2002). Esta bajada de impuestos anunciada ahora por Chirac ya fue esbozada por Juppé, pero la disolución de la AN de 1997 y el inicio de una nueva cohabitación puso fin a este proyecto. El nuevo Primer ministro, Jospin, no consideró conveniente esta medida y ha habido que esperar a estas elecciones para ver resurgir este tema, ahora como arma electoral.

124 Cfr. Le Monde, 02.03.02, pág. 9, en donde cinco economistas opinan, en general con bastante incredulidad, sobre el programa financiero de Chirac.

125 En ellas se han tenido muy en cuenta las posiciones de los sindicatos. Estos hace tiempo que vienen denunciando el uso abusivo que tanto las empresas como la función pública hacen de las prejubilaciones (cfr. Le Monde, 02.04.02, pág. 9). 
Gobierno su pasividad en la adopción de la reforma y propone la creación de fondos de pensión individuales. Esto es criticado por Jospin porque - dice - introduce una ruptura en el sistema de repartición. Por su parte, el candidato socialista, dice que la reforma debe realizarse con urgencia y propone la habilitación de fondos de ahorro salarial para financiar las jubilaciones complementarias. Los planes sobre pensiones de Jospin parecen satisfacer a los verdes ${ }^{126}$. También es partidario de respetar el sistema de repartición el candidato comunista, Robert Hue ${ }^{127}$.

\section{IV.2.5. Familia}

Recupera protagonismo este tema, por determinados problemas de acuciante actualidad con él relacionados, a saber, entre otros: la existencia en Francia de muy distintos modos de vida (rural, urbano, metropolitano, etc.) y, por lo tanto, de modelos muy distintos de familia, el envejecimiento de la población, la baja natalidad o la necesidad de prestar una mayor atención a la educación, tanto dentro como fuera de la familia, como vía para poner freno a la conducta delictiva de los jóvenes desde los origenes ${ }^{128}$.

\section{IV.2.6. Reforma de la institución presidencial}

En general, los principales contendientes defienden una presidencia fuerte. Chirac se centra en su campaña en los logros conseguidos durante el gobierno Juppé (1995-1995) periodo durante el cual gobernó realmente. Jospin, por su parte califica la cohabitación como uno de los peores males del país, pues impide la adopción de reformas y dice que, cuando la misma concluya, Francia recuperará su capacidad de proposición e innovación en Europa, si es posible, con el acuerdo de Alemania ${ }^{129}$.

126 Cfr. Le Monde, 20.04.02.

127 Cfr. Le Monde, 06.03.02.

128 Jospin quiere crear un «modelo francés» de familia. Como medidas propone la emisión de "cheques por hijos" para ayudar a aumentar la natalidad, internados familiares para niños de entre 9 y 14 años con dificultades Cfr. Le Monde, 07.03.02, pág. 9.

129 Cfr. Le Monde, 01.03.02, pág. 14. 


\section{IV.2.7. Reforma del estatuto jurisdiccional del Presidente}

Los numerosos escándalos judiciales que han rodeado a la vida política han hecho que éste sea otro de los temas principales de estas elecciones. El candidato Jospin propone una reforma del estatuto jurisdiccional de la Presidencia que prevea la responsabilidad penal de los delitos cometidos durante la presidencia de la República, reforma que se llevaría a cabo tras la celebración de un referéndum ${ }^{130}$. Chirac, por su parte, también defiende la posibilidad de que el Presidente de la República responda ante los tribunales, si bien - matiza - dicha reforma se debe hacer con seriedad.

\section{IV.2.8. Descentralización}

Iniciada hace veinte años, la descentralización vuelve a tomar vigencia como proyecto. Su antecedente es la Ley de 2 de marzo de $1982^{131}$, que marcó la primera etapa de una nueva organización política y administrativa de Francia. Ahora los debates se centran sobre todo en la concreción y clarificación de competencias, así como en el futuro del "modelo francés" en el seno de la Unión Europea ${ }^{132}$.

\section{IV.2.9. Reforma de otras instituciones del Estado}

Destaca sobre todo la reforma del Senado y del Consejo Constitucional. Se persigue que el Senado pueda representar más amplia y directamente a todas las colectividades locales. En cuanto al Consejo Constitucional, el objetivo más declarado es que en el modo de provisión al cargo prime la competencia del jurista y exista menos politización.

130 Cfr. Le Monde, 01.03.02, pág. 6.

131 Ley $82-213$ relativa a los derechos y libertades de los municipios, los departamentos y las regiones. Su artículo $1 .^{\circ}$ dispone: "Los municipios, los departamentos y las regiones son administrados libremente por consejos elegidos".

132 Cfr. Le Monde, 01.03.02, pág. 12. 


\section{IV.2.9. Córcega}

Chirac desea la realización de la primera fase de los acuerdos de Matignon. Aprueba la idea de la transferencia de competencias y el plan de inversión. Por el contrario excluye cualquier segunda fase $y$ un referéndum sobre el futuro institucional de la isla ${ }^{133}$. Jospin, por su parte, evita cualquier referencia a las promesas contenidas en el preámbulo del proyecto de ley sobre Córcega, aprobado el 28.11.01 y evoca vagamente nuevas competencias, que centra principalmente en las regiones ${ }^{134}$.

\section{IV.3. Sondeos}

Hacia principios de febrero los sondeos preconizan poco margen de obtención de votos entre los dos principales candidatos a la presidencia y sitúan a Chevènement en un distante y estable tercer puesto ${ }^{135}$. Hacia mediados de febrero los dos principales candidatos siguen casi igualados, con una ligerísima ventaja de Chirac. El resto de candidatos les sigue a mucha distancia, unos estacionados, otros en retroceso ${ }^{136}$. Jospin asciende y los demás candidatos se estacionan o retroceden ${ }^{137}$.

133 Cfr. Le Monde, 18.04.02, pág. 10. En efecto, la citada consulta referendaria exigiría una reforma previa de la Constitución del mismo artículo 89, dedicado a la revisión, que prevé el referéndum como forma de ratificación del proyecto de revisión constitucional pero que en cambio dispone, en su apartado cuarto: «no se podrá iniciar ni proseguir ningún proyecto de revisión cuando el mismo atente contra la integridad del territorio".

134 Cfr. Le Monde, 17.03.02, pág. 7. Esto denota un fino cálculo político, dado que se desconoce cuántos votos socialistas acaparará Chevènement en la primera vuelta, pues, como es sabido, este candidato es hostil a cualquier tipo de transferencia del ejercicio de la soberanía hacia la isla, motivo que estuvo en el origen de su dimisión como Ministro del Interior del Gobierno Jospin.

135 Véase sondeo Ipsos de 02.02 .02 para Le Monde, y sondeo Sofres de la misma fecha para Le Figaro Magazine.

136 Por ejemplo, un sondeo BVA realizado del 14 al 16 de febrero entre 1.034 personas para Paris Match (21.02.02) arroja los siguientes resultados:

Primera vuelta: los candidatos están casi igualados con una ligera ventaja de Chirac. En la segunda vuelta aparecen igualados. Les sigue Le Pen con un $11 \%$, Chevènement con un $10 \%$, Arlette Laguiller con un $7 \%$, Noël Mamère con $6 \%$ y Robert Hue con $5 \%$.

137 Cfr. Le Monde, 14.02.02, pág. 9. 
Hacia principios de marzo se erosiona ligeramente el electorado de Chirac $^{138}$. En el mes de abril aparece como ganador en la primera vuelta (Jospin pierde dos puntos); les siguen a igual distancia Arlette Laguiller y Le Pen; después Chevenement y, finalmente, igualados, Mamère, Hue y Bayrou ${ }^{139}$. La situación de igualdad entre los dos principales candidatos se consolida en vísperas de la primera vuelta, pero con un claro ascenso de Le Pen (de un 13 a un $14 \%$ ) en el tercer puesto.

Otro dato digno de destacar en relación con los sondeos es que todos ellos señalan el escaso interés en estas elecciones por parte del electorado (dos de cada tres declara no estar interesado en la campaña), lo que puede ser síntoma de falta de seguridad, no sólo en la persona que se desea como Presidente, sino también y lo más importante, en el tipo de régimen que prefieren los franceses, es decir, si desean una nueva cohabitación o volver a la práctica clásica de la $V^{a}{ }^{a}$ República ${ }^{140}$.

\section{LA PRIMERA VUELTA DE 21 DE ABRIL DE 2002}

Los resultados de la primera vuelta son los siguientes:

138 Chevènement se esfuerza en sacar partido de esta situación presentando su candidatura como de "centro" y de "unión" (cfr. Le Monde, 07.03.02). En un sondeo Sofres de 8 y 9 de marzo, realizado con una muestra de 1.000 electores (cfr. Le Monde, 13.03.02), en la primera vuelta Le Pen se estabiliza en un tercer puesto (un $11 \%$ ) y Chevènement retrocede al quinto puesto $(7,5 \%)$, por detrás de Arlette Laguiller (9\%).

139 En cambio Laguiller retrocede a un 6-7\% (Le Monde, de 20.04.02, pág. 10).

140 Jerôme Jaffré interpreta este escaso interés de los franceses en la campaña como una consecuencia de la cohabitación, dado que, debido reparto de poderes que en virtud de la misma existe, sea cual sea el resultado, no habrá ningún saliente (ni Chirac, que lo es institucionalmente, ni Jospin, que lo es de hecho, pues ha dirigido la nación durante cinco años) lo que priva al electorado de una parte de su libertad de elección. Además, los franceses tienen en sus manos la elección del régimen (presidencial o parlamentario), según el cual quieren que funcione la $V$ República, en cuyo caso deberán ratificar en las elecciones legislativas lo expresado en las presidenciales o, en caso contrario, la reforma del quinquenato y la inversión del calendario no habrán servido de nada (cfr. "Présidentielle, malaise de l'électeur", en Le Monde, 06.03.02, pág. 117). 
RELACIÓN POR PORCENTAJE DE VOTOS OBTENIDOS 141

\begin{tabular}{lcc}
\hline & Votos & Porcentaje \\
\hline Jacques CHIRAC & 5.665 .855 & $19,88 \%$ \\
\hline Jean-Marie LE PEN & 4.804 .713 & $16,86 \%$ \\
\hline Lionel JOSPIN & 4.610 .113 & $16,18 \%$ \\
\hline François BAYROU & 1.949 .170 & $6,84 \%$ \\
\hline Arlette LAGUILLER & 1.630 .045 & $5,72 \%$ \\
\hline Jean-Pierre CHEVENEMENT & 1.518 .528 & $5,33 \%$ \\
\hline NoëI MAMÈRE & 1.495 .724 & $5,25 \%$ \\
\hline Olivier BESANCENOT & 1.210 .562 & $4,25 \%$ \\
\hline Jean SAINT-JOSSE & 1.204 .689 & $4,23 \%$ \\
\hline Alain MADELIN & 1.113 .484 & $3,91 \%$ \\
\hline Robert HUE & 960.480 & $3,37 \%$ \\
\hline Bruno MEGRET & 667.026 & $2,34 \%$ \\
\hline Christine TAUBIRA & 660.447 & $2,32 \%$ \\
\hline Corinne LEPAGE & 535.837 & $1,88 \%$ \\
\hline Christine BOUTIN & 339.112 & $1,19 \%$ \\
\hline Daniel GLUCKSTEIN & 132.686 & $0,47 \%$ \\
\hline
\end{tabular}

Inscritos: 41.194.689 - Votantes: 29.495.733 - Expresados: 28.498.471.

Los resultados de la primera vuelta cambian por completo el escenario previsto por los sondeos ${ }^{142}$. En primer lugar resulta elegido Jacques Chirac, sólo tres puntos por delante de Le Pen. Éste mejora sus resultados en sus bastiones y realiza una incursión en los departamentos rurales. La extrema derecha consigue en total un $19,20 \%$ de

141 Datos suministrados por la Embajada de Francia en España.

142 En efecto, los sondeos no han sabido predecir el avance de Le Pen, debido, probablemente al elevado índice de indecisión del electorado, que ha motivado que muchos de los electores de Le Pen hayan decidido su voto en las últimas semanas; el gran número de candidatos, que ha alterado el juego electoral tradicional, y la elevada abstención, de la que se estima que un $27 \%$ pertenece a la izquierda plural, un $20 \%$ a la derecha parlamentaria y sólo un $16 \%$ al FN (cfr. Le Monde, 24.04.02). Otro factor del poco acierto de los sondeos ha sido el secretismo del electorado de Le Pen (cfr. The Times, 06.05.02, pág. 5). 
los votos, frente al $19,70 \%$ de 1995 , si bien el resultado de Le Pen aumenta (un $16,86 \%$ frente al $15 \%$ de 1995). Se observa una erosión en el electorado de la derecha tradicional, pese a que en estas elecciones ha intentado mantenerse unida bajo la agrupación UEM. Los candidatos conservadores que se han presentado por su cuenta han obtenido un bajo porcentaje de votos, de forma que si se suman los resultados obtenidos por estos pequeños candidatos a los de Chirac se observa una erosión en el voto de la derecha tradicional respecto de las elecciones de 1995 (33,79\% frente a 39,42\%). Esto puede verse en el siguiente cuadro:

\section{RESULTADOS COMPARATIVOS OBTENIDOS POR LA LA DERECHA $Y$ EL CENTRO-DERECHA EN LA PRIMERA VUELTA DE LAS ELECCIONES PRESIDENCIALES DE 1995 Y 2002}

\begin{tabular}{lllc}
\hline & $\begin{array}{c}\text { Presidenciales } \\
\text { de 1995 }\end{array}$ & & $\begin{array}{c}\text { Presidenciales } \\
\text { de 2002 }\end{array}$ \\
\hline Chirac (RPR) & $20,84 \%$ & Chirac (RPR) & $19,88 \%$ \\
\hline Balladur (RPR) & $18,58 \%$ & Bayrou (UDF) & $6,84 \%$ \\
\hline & Madelin 3,91\% & $1,88 \%$ \\
\hline & Lepage & $1,19 \%$ \\
\hline Total derecha & $39,42 \%$ & Boutin & $33,70 \%$ \\
\hline
\end{tabular}

Una de las causas de esta bajada en el voto de derechas puede ser, al igual que veíamos con los resultados obtenidos por la izquier$\mathrm{da}$, la elevada abstención verificada en esta primera vuelta $(27,86 \%)^{143}$. En ambos casos es muestra de la apatía del electorado hacia dos programas electorales que, pese a partir de ideologías distintas, no presentan, como ha quedado dicho, diferencia dignas de resaltar ${ }^{144}$.

El ultraderechista Le Pen queda en segundo lugar, aventajando ligeramente a Jospin y quedando por detrás de Chirac en algo más de

143 Este porcentaje de abstención es el mayor recogido en unas elecciones presidenciales en la $\vee$ República, mayor incluso que el de las elecciones de 1969 (un $22,4 \%$ ).

144 Cfr. supra, pág. 29. 
tres puntos. Es la primera vez que la extrema derecha pasa a la segunda vuelta en unas elecciones presidenciales. Estos inesperados resultados, con treinta y cinco departamentos ganados por el Frente Nacional, provocan el anuncio de Jospin de retirarse de la política tras las elecciones presidenciales y plantean una perspectiva totalmente nueva para el presidente saliente, que ahora tendrá que contender con el líder ultraderechista.

Respecto del resto de candidatos, lo más destacable es el discreto porcentaje de votos obtenido por Jean Pierre Chevènement $(5,34 \%)$, que ya no le permite jugar el papel de "tercer hombre" al que los sondeos del mes de febrero le permitían aspirar. En realidad ese $5,34 \%$ arrebatado a Jospin puede considerarse uno de los factores decisivos de la derrota socialista ${ }^{145}$, junto con el mayor nivel de abstención del electorado ${ }^{146}$. Otro dato digno de destacarse es total descalabro de Robert Hue, candidato del PCF, cuyo resultado, sólo de un $3,37 \%$ (frente al $8,64 \%$ obtenido en 1995) constituye un fracaso electoral sin precedentes, que muestra una emigración de gran parte de sus votos a otros candidatos de extrema izquierda como Arlette Laguiller de LO (que obtiene 5,72 frente al 5,30 de 1995), Noël Mamère, de los Verdes, (que consigue $5,25 \%$ frente al 3,20\% obtenido por Dominique Voynet en 1995), así como a otros nuevos candidatos de extrema izquierda con partidos de más reciente creación como Olivier Besancenot de la LCR (que obtiene un 4,25\%) o Christine Taubira, del PRG (que consigue un resultado de un 2,32\%). El PCF parece no haberse desligado del antiguo modelo comunista. Esta falta de adecuación del PCF a los nuevos problemas sociales y los nuevos conflictos surgidos con los emigrantes indocumentados, han ido dirigiendo el voto de inmigrantes $y$ otras minorias étnicas o sociales a otros partidos de izquierda alternativa.

145 En efecto, sumando ese 5,34\% al $16,18 \%$ obtenido por Jospin, el resultado habría sido de un $21,52 \%$, lo que le hubiera permitido a Jospin encabezar la segunda vuelta (en este sentido cfr. El País, 23.04.02, pág. 4).

146 Sobre este fracaso multifactorial del PS véase el interesante análisis de Duhamel en Le Monde, 24.04.02, pág. 16. 


\section{RESULTADOS COMPARATIVOS OBTENIDOS POR LA IZQUIERDA EXTREMA Y MODERADA EN LA PRIMERA VUELTA DE LAS ELECCIONES PRESIDENCIALES DE 1995 Y 2002}

\begin{tabular}{|c|c|c|c|}
\hline & $\begin{array}{c}\text { Presidenciales } \\
\text { de } 1995\end{array}$ & & $\begin{array}{l}\text { Presidenciales } \\
\text { de } 2002\end{array}$ \\
\hline \multirow[t]{2}{*}{ Jospin (PS) } & $23,30 \%$ & Jospin (PS) & $16,18 \%$ \\
\hline & & Chèvenement (PR) & $5,33 \%$ \\
\hline Hue (PCF) & $8,64 \%$ & Hue (PCF) & $3,37 \%$ \\
\hline Voynet (Verdes) & $3,32 \%$ & Mamère (Verdes) & $5,25 \%$ \\
\hline \multirow[t]{2}{*}{$\begin{array}{l}\text { Cheminade } \\
\text { (Nueva solidaridad) }\end{array}$} & $0,28 \%$ & Besancenot (LCR) & $4,25 \%$ \\
\hline & & Taubira (PRG) & $2,32 \%$ \\
\hline Izquierda moderada & $23,30 \%$ & Izquierda moderada & $21,51 \%$ \\
\hline Extrema izquierda & $12,24 \%$ & Extrema izquierda & $15,19 \%$ \\
\hline Total izquierda & $35,54 \%$ & Total izquierda & $36,70 \%$ \\
\hline
\end{tabular}

El reparto anterior de los votos de izquierda muestra un voto de castigo contra la política del gobierno ${ }^{147}$, algo que suele ser habitual en la primera vuelta de las elecciones francesas ${ }^{148}$. Paradójicamente el imprevisto resultado de Le Pen motivará que esta izquierda, que ha fracasado en llevar a cabo un proyecto común, deba ahora unirse precisamente para votar a la derecha y frenar así el avance de la extrema derecha.

A continuación veremos el avance de la extrema durante las últimas elecciones presidenciales ${ }^{149}$ :

147 Este voto de castigo puede deberse también al ostensible viraje el centro que Jospin ha hecho en la campaña de estas elecciones, calificando su proyecto como un proyecto no socialista, o sólo "socialista de inspiración". También se ha castigado a Hue (PCF) al que a menudo se ha acusado de plegarse a la política del gobierno.

148 Se dice que los franceses votan en la primera vuelta con el corazón y en la segunda con la razón. En este sentido, cfr. Le Monde, 28-29 de abril de 2002, págs. 1-22, donde una serie de analistas califican el voto de esta primera vuelta como un "voto de crisis", crisis de la política y de la sociedad, voto que no pretende designar la persona que debe ejercer la carga suprema, sino expresar un voto de humor y de protesta, designando inicialmente a un candidato que no se quiere realmente como gobernante, para mandar un mensaje a "los de arriba", es decir, a los que verdaderamente resultarán elegidos en la segunda vuelta.

149 Los datos de las elecciones presidenciales anteriores se han tomado de Brechon, Pierre, op. cit., págs. 44 y ss. 


\section{RESULTADOS DE LA EXTREMA DERECHA EN LAS ELECCIONES PRESIDENCIALES (1974-2002)}

\begin{tabular}{|c|c|c|}
\hline * & $\begin{array}{c}\text { Primera vuelta } \\
\text { en \% de los votos } \\
\text { expresados }\end{array}$ & $\begin{array}{c}\text { Segunda vuelta } \\
\text { en } \% \text { de los votos } \\
\text { expresados }\end{array}$ \\
\hline \multicolumn{3}{|l|}{ Elecciones presidenciales de $1974:$} \\
\hline Le Pen & $0,8 \%$ & \\
\hline Total extrema derecha & $0,8 \%$ & $(*)^{150}$ \\
\hline Elecciones presidenciales de 1981: & $(*)^{151}$ & \\
\hline \multicolumn{3}{|l|}{ Elecciones presidenciales de 1988 : } \\
\hline Le Pen & $14,4 \%$ & \\
\hline Total extrema derecha & $14,4 \%$ & $(*)^{152}$ \\
\hline \multicolumn{3}{|l|}{ Elecciones presidenciales de 1995: } \\
\hline Le Pen & $15,0 \%$ & \\
\hline De Villiers & $4,7 \%$ & \\
\hline Total extrema derecha & $19,7 \%$ & $(*)^{153}$ \\
\hline \multicolumn{3}{|l|}{ Elecciones presidenciales de 2002: } \\
\hline Le Pen & $16,9 \%$ & \\
\hline Mégret & $2,3 \%$ & \\
\hline Total extrema derecha & $19,2 \%$ & $17,79 \% 154$ \\
\hline
\end{tabular}

150 En la segunda vuelta le Pen llamó al voto a favor de Giscard d'Estaing.

151 Ni Le Pen, ni Gauchon, líder del PFN consiguen reunir las quinientas firmas necesarias para su candidatura.

152 En la segunda vuelta, Le Pen dejó elegir a sus votantes entre Jacques Chirac y la abstención, indicando que ningún voto debía de ir a Mitterrand.

153 En esta segunda vuelta deja libertad a sus electores, si bien anuncia que él votará en blanco. Sin embargo, merece destacarse que una parte de esos votos de Le Pen irán a Jospin en la segunda vuelta (aproximadamente un cuarto de los votos, mientras que la mitad irán a Chirac y el otro cuarto a la abstención). Cfr. BreCHON, Pierre, op. cit., pág. 65.

154 Porcentaje obtenido por Le Pen en la segunda vuelta, que muestra que este candidato no ha conseguir recuperar todos los votos fugados a Bruno Mégret en la primera vuelta. Véase el cuadro con los datos de la segunda vuelta, infra. 
Los resultados por circunscripciones de las presentes elecciones muestran la implantación de Le Pen en el este de Francia. Paralelamente sigue siendo apreciable, al igual que ocurrió en las elecciones presidenciales de 1995, la afluencia hacia este movimiento de electores tradicionalmente de izquierdas ${ }^{155}$. Los resultados obtenidos por este candidato populista en estas elecciones y su mantenimiento en la segunda vuelta, nos obligan a realizar una pequeña exposición sobre el nacimiento del FN, su ideología y su evolución en las elecciones francesas.

Los orígenes de la extrema derecha en Francia pueden situarse en la "derecha contestataria" de 1940, concebida por el Mariscal Petain como reacción a las ideas de la Revolución francesa, oponiendo al eslogan "Libertad, Igualdad, Fraternidad", el de "Trabajo, Familia, Patria" $y$ al individualismo de la antigua sociedad francesa el comunitarismo y corporativismo. Este movimiento sucumbió ante las fuerzas políticas que surgieron durante la Resistencia, pero el nacional-socialismo emergería más tarde de la mano de Pierre Poujade, que en 1953 creó la Unión de defensa de los comerciantes y artesanos (UDCA), que empezó siendo un movimiento sindical, pero que rápidamente se politizó adoptando un discurso propio de la derecha nacional y populista, que no consiguió hacerse valer electoralmente (el conjunto de la extrema derecha apenas obtuvo un $2 \%$ en las elecciones legislativas de1958) pero que permaneció como tradición ideológica susceptible de ser reactivada dadas las circunstancias adecuadas, algo que sucedería con la solución del problema de Argelia. Pese a todo, las fuerzas políticas de extrema derecha siguieron sin obtener resultados relevantes en las elecciones legislativas de 1962 y en las presidenciales de 1965 , si bien se apreciaba un mayor porcentaje de votos en ciudades del sur receptoras de los franceses de Argelia, que en cualquier caso no pasaría del $5,2 \%$ en toda Francia. A partir de entonces la extrema derecha conocería un largo período de retroceso (en las elecciones legislativas de 1967 sólo obtuvo un $0,8 \%$ de los sufragios) que se mantendria con pocas modificaciones hasta las elecciones europeas de

155 Entre sus electores hay maestros, padres de alumnos, contribuyentes, pequeños empresarios, arrendatarios de viviendas de protección oficial o incluso miembros la Policía (cfr. Le Monde, 27.04.02, págs. 1 y 2). Asimismo cfr. Le Monde, 03.05.02, pág. 16, donde se da a conocer un estudio según el cual el orden de preferencia de voto de los 7.000.000 de obreros que tiene Francia sería el siguiente: Le Pen, Chirac, Jospin, Laguiller, Saint-Josse. El factor determinante de esta preferencia es la xenofobia. También se observa un progreso de la extrema derecha en las ciudades mineras, por ejemplo en Moselle. Alsacia constituye desde 1984 un bastión de la extrema derecha (cfr. Le Monde, 29.05.02, págs. 14, y 30.05.02, pág. 14). 
1979, en las que, bajo otro nombre (Partido de Fuerzas Nuevas o PFN) obtuvo un resultado algo superior $(1,3 \%)$. La escalada de la extrema derecha se iniciaría con las elecciones municipales de 1983, tras una campaña centrada en la excesiva inmigración como factor del desempleo y en la inseguridad. Curiosamente los mejores resultados se obtuvieron en los barrios obreros, donde el voto se había dirigido tradicionalmente a la izquierda, pero también se dio una progresión en determinados contextos urbanos. Las elecciones cantonales de 1985 demostrarían que el FN tenía una buena implantación local. Esta situación se mantendría con pocos cambios en las elecciones legislativas de 1986 (un análisis pormenorizado muestra que el FN refuerza sus bastiones en la parte sur-mediterránea). En las elecciones regionales de ese año, celebradas el mismo día que las legislativas, el FN obtuvo un resultado similar: $9,5 \%$ de los sufragios. Sin embargo, la escalada de este partido no tendría lugar hasta las elecciones presidenciales de 1988, para las que Le Pen intentó rodearse de personalidades de cierto prestigio, como Bruno Mégret, diputado del FN, alto funcionario y tránsfuga de la RPR, elecciones en las que el FN obtuvo el $14,4 \%$ de los sufragios expresados, no muy lejos de Raymond Barre y Jacques Chirac. Cabe destacar los resultados conseguidos en Alsacia, donde el terreno era favorable al antieuropeísmo y al nacionalismo, y en determinados departamentos rurales con estructuras sociales tradicionales. En contraste, las elecciones legislativas de 1988 supondrían un retroceso en la escalada del FN, que sólo obtuvo un $9,6 \%$, resultado muy próximo a las legislativas de 1986 . Este reflujo se confirmó en - las cantonales de septiembre de 1988 (un 5,2\% en toda Francia). Las elecciones municipales de marzo de 1989 constituyeron para el FN una difícil prueba, dado que no disponía de medios para presentar candidatos en todos los municipios de Francia, de modo que sólo obtuvo un $2,5 \%$ de los sufragios expresados en todo el país (obviamente los resultados fueron comparativamente más elevados en los municipios donde logró presentarse:10,10\% de los votos en 214 municipios de más de 20.000 habitantes). Sin embargo, esta leve recesión del FN cesaría con las elecciones europeas de 1989, en las que el FN obtuvo un $11,8 \%$ de los sufragios expresados. Este resultado, relativamente bueno teniendo en cuenta el alto indice de abstención, demuestra la buena movilización de su electorado. Tras estas elecciones, la coyuntura económica de otoño de 1989 se revelará como muy favorable para el FN, dado que en estas fechas cobran fuerza los problemas sociales relacionados con los emigrantes, lo que reforzará la xenofobia latente de una parte de la población francesa. Los buenos resultados obtenidos por el FN en unas elecciones legislativas parciales celebradas en 
noviembre y diciembre de 1989 en dos circunscripciones, Dreux y Marsella, llevan a Le Pen a creer que puede transformar su partido en una fuerza de gobierno. A principios de 1992, la intención de voto al FN se estima entre un 13 y un $15 \%$. Esta anunciada progresión se confirmará en las elecciones regionales y cantonales de marzo de 1992, en las que el FN experimenta una importante progresión respecto de las regionales de 1986 y cantonales de 1985 (13,9\% en las regionales y 12,4 en las cantonales), avance que se encuentra bastante bien repartido geográficamente. En 1992 el Frente Nacional se compromete fuertemente en la lucha contra la ratificación de Tratado de Maastricht. Posteriormente, en la primera vuelta de las elecciones legislativas de marzo de 1993 el FN obtiene un 12,4\%, lo que resulta un buen porcentaje si se compara con las legislativas de 1988, resultado éste que representa un avance de tres puntos respecto de las legislativas de 1988. Este resultado le permite pasar en unas cien circunscripciones a la segunda vuelta, si bien no consigue sacar el máximo partido de ésta, debido al aislamiento del movimiento y a la desafección de una parte del electorado de derechas de la primera vuelta en las situaciones de duales con la izquierda, mientras que en otros casos de duales con la derecha es el aporte de votos suplementarios de izquierda al candidato de derechas o que le hace fracasar. En las cantonales celebradas un año más tarde, en 1994, tampoco consigue resultados muy elevados, aunque si superiores en un punto a los de las cantonales de 1985 (un $9,8 \%$ ), si bien está presente en casi todos los cantones, lo que demuestra su implantación. Por el contrario, en las elecciones europeas de ese mismo año obtiene resultados algo inferiores a los de 1989: un 10,50\% de los sufragios expresados (un 1,3\% menos que en las citadas elecciones). En la primera vuelta de las presidenciales de 1995 obtiene, pese a la competencia del otro candidato de extrema derecha, Villiers, un $15 \%$ de los votos expresados, debido en parte a determinadas medidas propuestas por el Ministro del Interior, Edouard Balladur, para facilitar la acogida de inmigrantes, con lo que supera el récord de 1988, éxito éste confirmado en las elecciones municipales, en las que consigue tres ciudades importantes del sur de Francia: Toulon, Marignane y Orange. Otro punto interesante es que se estima que en estas elecciones vota a Le Pen un $12 \%$ de los electores que en 1988 lo hicieron a Mitterrand ${ }^{156}$. Todo ello determina que Le Pen se convierta en estos

156 Este fenómeno ha hecho que se haya podido hablar de un lepenismo de izquierdas (gaucho-lepenisme). En este sentido, cfr. PerRINEAU, Pascal, "La dynamique du vote Le Pen. Le poids du gaucho-lepénisme», cit. en BRECHON, Pierre, op. cit., pág. 65 . 
comicios en el árbitro del resultado electoral definitivo que dará la victoria a Chirac, de modo que, por primera vez en la V República la extrema derecha y la ultraderecha nacionalista están en situación de imponer su criterio ${ }^{157}$. Durante la campaña de las elecciones legislativas de 1997 la extrema derecha (ahora dividida entre el FN de Le Pen y el MNR de Mégret) acusa las críticas cada vez más agudas de la sociedad francesa, que lo considera una amenaza para la democracia. Sin embargo los resultados obtenidos confirman los de la elección presidencial $(15,1 \%$, del que un $14,9 \%$ lo obtiene el FN, 2,4 más puntos respecto de 1993, lo que le permite mantenerse en 133 circunscripciones). A partir de ese momento el $\mathrm{FN}$ aparece como una fuerza política bien implantada en el conjunto del territorio. De 1993 a 1997 la progresión del FN es mayor en el nordeste de Francia, concretamente en Alsa$\mathrm{cia}^{158}$. En las elecciones municipales de 2001 los resultados obtenidos por la extrema derecha (FN y MNR) parecen indicar un debilitamiento respecto de 1995, si bien sigue conservando sus bastiones de Orange, Marignane y Vitrolles ${ }^{159}$.

En las presentes elecciones presidenciales de 2002 el FN ha conocido su mejor resultado histórico, no sólo por el porcentaje de votos, que ha sido superior casi en dos puntos al de 1995 (un 16,86\% en la primera vuelta frente a al $15 \%$ obtenido en las presidenciales de 1995), sino también por la elevada abstención, la mayor desde la segunda vuelta de las elecciones presidenciales de1969160, la gran dispersión de los votos de izquierda y la relativa unión de la derecha y centro-derecha tradicionales, factores estos que le han permitido pasar a la segunda vuelta, convirtiéndose así en el principal contendiente de Chirac y planteando así un escenario totalmente insólito hasta la fecha en unas elecciones francesas: el de la derecha tradicional contra extrema derecha. Además, es la primera vez desde 1969 que no existe ningún candidato de izquierdas en la segunda vuelta de unas elecciones presidenciales.

157 Esto obligará a Chirac a modificar algo su discurso, para ganarse el apoyo de Le Pen, pero no demasiado, pues es consciente de que ese mismo voto le podria hipotecar durante su mandato (cfr. GoIg MARTinez, Juan Manuel, op. cit., pág. 331).

158 En la exposición que antecede nos hemos guiado preferentemente por el estudio realizado por BRECHON, Pierre, La France aux urnes, 1998, París, La Documentatation Française, 1998, págs. 43 y ss.

159 Cfr. mi estudio "Las elecciones municipales en Francia de 11 y 18 de marzo de 2001 ", en Revista de Estudios Políticos, julio-septiembre 2001, Madrid, Centro de Estudios Políticos y Constitucionales, 2001.

160 Dato tomado de Le Monde, 23.04.02, pág. 27. 
La doctrina del Frente Nacional puede resumirse del siguiente modo: deliberadamente liberal en el terreno económico, el FN propugna un "capitalismo popular" y censura el intervencionismo estatal, que aligera el sentido de responsabilidad de los individuos. En el terreno político acepta el modelo republicano, pero prefiere la democracia directa (relación directa entre la nación y el presidente), a una democracia representativa. Otro punto importante en la ideología del FN es la defensa del Estado como un bien preciado, lo que le lleva al rechazo de los inmigrantes, porque constituyen una amenaza para la identidad nacional. Estas posiciones, en las que la derecha popular, social y nacional parece primar sobre las ideas más extremistas, contrastan con la polémica suscitada por los discursos de Le Pen, en especial uno pronunciado en 1987, en el que Le Pen calificaba el exterminio nazi de "detalle de la historia»161. Lo cierto es que del Frente Nacional se sabe muy bien lo que rechaza (la inmigración, el islamismo, la Unión Europea, etc.) pero se conoce muy poco de sus proyectos. Se trata de un partido muy personalizado en la figura de Le Pen y con una doctrina política, social y económica poco elaborada, de modo que muchas de sus manifestaciones a veces no parecen muy distintas de las propias de un partido socialdemócrata ${ }^{162}$.

\section{LA SEGUNDA VUELTA DE DE 5 DE MAYO DE 2002}

En los días inmediatos a conocerse los resultados de la primera vuelta el Partido socialista, el Partido comunista francés, el Polo Republicano de Chevènement y los Verdes hacen una llamada a la disciplina republicana y al voto útil, pidiendo el voto de la izquierda para Chirac, con el fin de frenar el avance de Le Pen y salvaguardar los valores democráticos ${ }^{163}$. También los Verdes piden el voto para Chirac. Sólo LO y la LCR, los dos partidos trotskistas, se niegan a apoyar a Chirac.

161 Cfr. ídem, id., pág. 48 y ss.

162 Un ejemplo de ello es el modo en el que Le Pen se ha autodefinido en estas elecciones: "Soy socialmente de izquierdas y económicamente de derechas" (cfr. Le Monde, 27.04.02, pág. 3).

163 Cfr. El País, 23.04.02. Asimismo El Mundo (23.04.02) señala: «La izquierda llama a votar a Chirac con dolor en el alma". Jospin no llamará al voto por la derecha hasta el 26 de abril, fecha en la que declara su descontento por la elección que se presenta y rebate el programa del FN (cfr. Le Monde, 28-19.04.02, pág. 3). El Mundo (20.04.02, pág. 20) recoge el llamamiento de los partidos al voto por Chirac como mal menor. 
Simultáneamente se suceden las manifestaciones en París y en las principales ciudades francesas contra el racismo y la intolerancia que Le Pen representa, de las que cabe destacar la del primero de mayo, en la que participan un millón y medio de franceses ${ }^{164}$. Sin embargo en estas manifestaciones de apoyo a Chirac se intenta dejar claro que el objetivo es defender la República y que en ningún caso se está aprobando la gestión de Chirac al frente del Elíseo ${ }^{165 .}$

Le Pen, que también organiza una manifestación el primero de mayo en la que, sin embargo, sólo consigue reunir a 30.000 fieles ${ }^{166}$, pide el voto de la izquierda para la segunda vuelta, porque la considera victima de una maniobra urdida por Chirac para eliminarla, consistente en engordar los votos de la extrema derecha mediante el refuerzo de su discurso en materia de seguridad, para así ganar más fácilmente las elecciones, algo que habría tenido muy difícil de tener enfrente a Jospin ${ }^{167}$. Simultáneamente busca apoyo en alianzas extranjeras, como dudoso éxito, pues los dirigentes de los partidos europeos de extrema derecha juzgan su partido demasiado extremista ${ }^{168}$.

Chirac, a quien la subida de Le Pen ha favorecido electoralmente al garantizarle su reelección, no puede pasar por alto el mensaje lanzado por los electores en la primera vuelta, mensaje que pone en tela de juicio todo el sistema político francés. En consecuencia, llama a la unión contra la ultraderecha y asegura haber entendido la inquietud de los franceses. En los días posteriores a esta primera vuelta vuelve a hablar de la inseguridad y evoca, por primera vez, la inmigración. También se dirige a los pequeños asalariados, muchos de los cuales han votado al $\mathrm{FN}^{169}$. Los integrantes del centro y de la derecha moderada se unen bajo las siglas UMP (Unión por la mayoria presidencial), denominación bajo la cual se pretende, con el apoyo consabido de la izquierda en el caso de triangulares con la extrema derecha, ganar las elecciones legislativas.

164 Cfr. Le Monde, 03.05.02 y El Mundo 02.05.2002 (en la manifestación participa la izquierda plural y los ministros, así como todos los jóvenes de partido de la izquierda plural y de la extrema izquierda).

165 Cfr. The Daily Telegraph, 07.05.02, pág. 17, que, recogiendo este sentir popular, se hace al mismo tiempo eco de los escándalos financieros que han salpicado a al presidente saliente en relación con su gestión como alcalde de París

166 Cfr. El País, 02.05.02., pág. 3.

167 Cfr. Le Monde, 28-29.04.02, pág. 10, y El Mundo, 02.05.02, pág. 18.

168 Cfr. Le Monde, 27.04.02, pág. 3.

169 Cfr. Le Monde, 27.04.02, pág. 6. 
El Partido Socialista, mientras brinda su apoyo a Chirac en la segunda vuelta de las presidenciales, como único medio de garantizar la pervivencia de la democracia, espera que la concienciación de sus electores sobre los resultados a los que ha conducido la elevada abstención y la dispersión del voto de izquierda le ayude a recuperar en las elecciones legislativas los votos huidos en las presidenciales y no excluye, desdiciéndose de lo defendido en la campaña electoral de marzo y abril, la posibilidad de una cohabitación ${ }^{170}$.

Los resultados de la segunda vuelta son los siguientes:

\section{RESULTADOS DEFINITIVOS DE LA ELECCIÓN PRESIDENCIAL} DE $2002^{171}$

\begin{tabular}{lcc}
\hline & Número & Inscritos en \% \\
\hline Inscritos: & 41.191 .151 & \\
\hline Abstenciones & 8.359 .650 & $20,29 \%$ \\
\hline Votantes & 32.831 .501 & $79,71 \%$ \\
\hline Expresados & 31.066 .781 & $75,42 \%$ \\
\hline & Votos & Expresados en\% \\
\hline JACQUES CHIRAC & 25.540 .874 & $82,21 \%$ \\
\hline JEAN-MARIE LE PEN & 5.525 .907 & $17,79 \%$ \\
\hline
\end{tabular}

Los resultados de la segunda vuelta otorgan una victoria a Chirac sin precedentes (un $82,21 \%$ ), mayor aún que la pronosticada por los sondeos ${ }^{172}$. Los franceses han sabido hacer un frente común, más allá de las ideologías, para preservar la República y los principios democráticos del Estado. La amenaza de la extrema derecha ha sabido movilizar a gran parte de los abstencionistas, cuyo porcentaje baja en esta segunda vuelta a $20,29 \%$ frente al $27,86 \%$ de la primera vuelta. En cambio aumentan significativamente los votos en blanco o nulos, que alcanzan un $4,29 \%$ (frente al $3,37 \%$ de la primera vuelta), lo que denota una clara de disconformidad hacia las dos formaciones

\footnotetext{
170 Cfr. supra pág. 19, y The Daily Telegraph, 23.04.02, pág. 4.

171 Datos suministrados por la Embajada de Francia en España.

172 Cfr. sondeo CSA publicado en Le Parísien, 30.04.02.
} 
políticas principales. En cambio el líder ultraderechista obtiene sólo 50.000 votos más que el total de la extrema derecha en la primera vuelta, de forma que puede decirse que este resultado delimita la exacta dimensión del FN ${ }^{173}$.

Este asalto fallido del FN y la final victoria de Chirac en las presentes elecciones municipales provoca también la reacción de la prensa extranjera, que se hace eco de la gran mayoría obtenida por Chirac en estas elecciones (la mayor de la $V$ República) ${ }^{174}$ y recoge el temor de la subida de la extrema derecha en Francia y en Europa ${ }^{175}$. Asimismo se suceden las manifestaciones de rechazo de los principales líderes europeos, preocupados porque los partidos de extrema derecha de muchos países europeos están obteniendo buenos resultados en las urnas utilizando la retórica de la lucha contra la inmigración ${ }^{176}$.

Tras conocerse los resultados de la segunda vuelta Chirac manifiesta su adhesión a los valores de la República. Su victoria arrolladora le permitirá, si se confirma en las legislativas, volver a ser un Presidente fuerte al estilo clásico de la $V$ República y dejar atrás los cinco años de cohabitación, que para algunos analistas está, junto con la

\section{Cfr. Le Monde, 7.05.2002.}

174 Por ejemplo, cfr. The Times, 06.05.02.

175 Cfr. Ídem, pág. 5. En efecto, el asesinato de Pim Fortuyn, líder de la extrema derecha en Holanda, en vísperas de las elecciones generales holandesas aumenta el sindrome de terror creado con los resultados de la primera vuelta de las elecciones francesas. En este sentido es interesante cfr. The Daily Telegraph, 07.05.02. En su editorial (p. 19) considera un error típico de los analistas de izquierda asimilar el caso Le Pen al caso Fortuyn, que, a diferencia de Le Pen, no era tanto un fascista como un hombre anti-sistema, que atacaba el cártel gubernamental holandés que, al igual que en la mayoría de los países de la UE, intenta crear un club de los partidarios del sistema, con coaliciones para crear consenso en temas como la emigración, la integración europea, etc. En relación con este tema, el mismo diario señalaba en su editorial de 23.04.02 que Le Pen no es un hombre de derechas en el sentido británico del término, sino un hombre "anti-todo»: anti-Europa, anti-América, anti-Jospin, anti-Chirac, etc.

176 Cfr. algunas de estas manifestaciones las recoge en el The Daily Telegraph, 23.04.02, pág. 4, así como las declaraciones del Comisario europeo Neil Kinnock. El Canciller alemán Schröder evita comentar el tema personalmente (ídem, id.). Posteriormente declara en compañía de Romano Prodi, Comisario de la UE; que el éxito de Le Pen aconseja frenar la Unión Europea, a lo que Prodi responde que el antidoto de la extrema derecha es "más Europa» (cfr. El País, 01.05.02). Recordamos que este cruce de opiniones se produce tras los reproches lanzados por Berlín contra la Comisión Europea, en relación con las iniciativas legales comunitarias que afectan principalmente a la industria alemana. 
Unión Europea, en el origen de la escalada ultraderechista ${ }^{177}$. Por el momento, encabezando la cruzada contra el Frente Nacional, saca partido a su imagen, propiciada por los resultados citados, de artífice de la unidad nacional o, como establece el mismo artículo 5 de la Constitución francesa, de árbitro en el aseguramiento del funcionamiento regular de los poderes públicos y de la continuidad del Estado por encima de los partidos o de las ideologías. Sin embargo, pese a esta imagen, que Chirac intentará explotar al máximo, el presidente reelegido no puede pasar por alto que los franceses están pidiendo un cambio real en el modo de gobernar, algo que el Presidente lleva prometiendo desde que ascendió por primera vez a la Presidencia de la República, sin llevarlo a cabo. Consciente del mensaje lanzado por el pueblo francés en estas elecciones presidenciales, el líder de la RPR promete un cambio de política ${ }^{178}$. Con este clima político se inicia la campaña de las elecciones legislativas.

\section{LAS ELECCIONES LEGISLATIVAS DE MAYO Y JUNIO DE 2002}

\section{INTRODUCCIÓN}

Estas elecciones no pueden considerarse de forma separada de las elecciones presidenciales, por varios factores. En primer lugar el de su proximidad o el de su casi coincidencia temporal, cosa que se ha intentado conseguir con la reducción del mandato presidencial a cinco años, si bien pensamos que con dudoso éxito, como ha quedado expuesto ${ }^{179}$. Esta proximidad pretende en efecto conseguir que mayoría presidencial y mayoría parlamentaria coincidan, si bien la

177 En este sentido véase el editorial del 06.05.02 de The Daily Telegraph, pág. 19. Este análisis sitúa la cohabitación (que ahora los socialistas quieren recuperar) y la creación de la Unión Europea en el origen de la escalada ultraderechista, recordando que cuando se inició la puesta en práctica del Tratado de Maastricht los euroescépticos predijeron la emergencia de extremismos, debido a que con la reducción del principio de inmediación que implica la puesta en práctica de la Unión Europea, los gobernados podrían sentir que el sistema era incapaz de dar respuesta a sus problemas inmediatos. Recordemos que uno de los defectos que más se reprocha a la la cohabitación es que la obligada convivencia entre dos jefes del Ejecutivo de ideologías distintas puede frenar en cierto modo la adopción de reformas, con lo que aumenta también la insatisfacción del electorado.

178 Cfr. The Daily Telegraph, 06.05.02.

179 Cfr. supra, pág. 7. 
posibilidad de que ambas diverjan no queda totalmente excluida. Lo hemos podido ver en los presentes comicios, en los que el desconcertante resultado de la primera vuelta $y$ el subsiguiente voto útil en torno a Chirac en la segunda vuelta no excluian la posibilidad de una organización del electorado de izquierdas en las legislativas, lo que habría desembocado en una nueva cohabitación. No ha sido éste el deseo del electorado, que parece haber quedado harto de cinco años de coexistencia institucional y así lo ha hecho saber a la nación, ratificando en las legislativas su decisión definitiva de las presidenciales. El segundo factor está relacionado con el primero y viene determinado por el propio sistema de la $V$ República, que ha dado lugar, bajo un mismo texto constitucional, a dos formas de gobernar totalmente distintas, una con coexistencia institucional, la consabida cohabitación, en la que la forma de gobierno es parlamentaria, y otra sin coexistencia, en la que la forma de gobierno es fundamentalmente presidencial. Como esto último depende siempre del resultado de las elecciones legislativas y de la relación de este resultado con la mayoría presidencial existente, las elecciones legislativas pueden considerase siempre como otra vuelta, que confirma o da la vuelta a los resultados de las presidenciales. La disolución de la Asamblea por Mitterrand en 1988, para homogeneizar ambas mayorías y poner asi fin a la cohabitación, o la disolución llevada a cabo por Chirac en 1997, que creó una cohabitación, en lugar de evitarla, confirman este punto.

\section{NORMAS APLICABLES A LAS ELECCIONES LEGISLATIVAS}

El artículo 24 de la Constitución francesa dispone, en su apartado primero: "El Parlamento comprende la Asamblea Nacional y el Senado. Los diputados de la Asamblea Nacional se eligen mediante sufragio directo". Son elegibles al cargo de diputado de la Asamblea Nacional los ciudadanos franceses que hayan cumplido veintitrés años de edad y tengan calidad de electores ${ }^{180}$.

Este mandato constitucional se completa con las siguientes disposiciones del Código electoral.

180 Art. LO 127 del Código electoral (instituido por Ley orgánica n. ${ }^{\circ} 2000$ 294, de 5 de abril de 2000). Los siguientes artículos disponen varias causas de inelegibilidad, a saber: estar condenado, cuando la condena impida definitivamente o temporalmente su inscripción en una lista electoral (arts. LO 129 y LO 130), los que detentan determinados cargos o funciones. 
Art. L.123. "Los diputados se eligen por medio de escrutinio uninominal mayoritario a dos vueltas». El modo de elección mayoritario fue restablecido por Ley $\mathrm{n}^{\circ} 86-825$ de 11 de julio de 1986, art. 1 y Ley n. ${ }^{\circ} 86-1197$ de 24 de noviembre de 1986, art. 4 y 5, modificando así la Ley $n .^{\circ} 85-690$ de 10 de julio de 1985 que había instituido el sistema proporcional existente bajo la IV República ${ }^{181 .}$

\section{CAMPAÑA ELECTORAL}

Aunque la campaña de las legislativas empieza sobre el terreno con anterioridad a las elecciones presidenciales, los inesperados resultados en la primera vuelta de estos comicios y el cierre de filas producido en torno a Chirac como consecuencia del avance lepenista hace que la mayoría de los candidatos se desentiendan de la segunda vuelta y empiecen modificar su estrategia para las legislativas del mes siguiente, de modo que es en este momento en el que debe situarse el inicio real de esta segunda campaña electoral. A continuación resumimos la situación y la campaña realizada por las formaciones más importantes.

\section{II.1. Derecha y centro-derecha}

En el seno de la familia chiraquí se teme al efecto de unas posibles triangulares con el PS y la extrema derecha, si se confirma su escalada en las legislativas, lo cual podría hacer perder a la derecha las citadas elecciones. Se bajaran tres hipótesis: la primera, la menos ventajosa para la derecha, es una victoria del PS y la consiguiente cohabitación por otro periodo de cinco años; la segunda, la obtención por la derecha tradicional de una mayoría relativa en la Asamblea, pero con la entrada en de una izquierda fuerte y de la extrema derecha; por último, la tercera hipótesis es la de que la derecha gane por mayoría absoluta las citadas elecciones. Conscientes de este objetivo intentarán limitar sus divisiones. Juppé y Raffarin hacen una llamada a los electores para que se movilicen y den una victoria lo más holgada posible a la derecha ${ }^{182}$.

181 Esta reforma fue llevada a cabo por Mitterrand para paliar los efectos del escrutinio mayoritario en las elecciones legislativas de 1986, que habría propiciado que la derecha entrara en masa en la Asamblea. Con el sistema proporcional se buscó conseguir una dispersión del voto.

182 Cfr. Le Monde, 24.04.02, pág. 3. 
Chirac, ya presidente reelecto, nombra Primer Ministro a un hombre de centro, Jean-Pierre Raffarin ${ }^{183}$, hasta entonces vicepresidente de Democracia Liberal (DL), dando asi muestras de su ánimo de consenso y conciliación, si bien esta apertura al centro es limitada debido a la negativa de Douste-Blazy (RDF) de entrar en el Gobierno ${ }^{184}$. En realidad, pese al nombramiento de un hombre de centro al frente de Matignon, el nuevo equipo gubernamental es fundamentalmente un grupo de fieles a Chirac ${ }^{185}$, en el que las carteras clave se han reservado para miembros de la RPR. El nombre de Raffarin ya se barajó junto con el de Douste-Blazy, Alain Juppé (RPR) y Nicolás Sarkozy (RPR) durante la campaña de las elecciones presidenciales ${ }^{186}$. Con este giro simbólico al centro Chirac quiere contentar, dando muestras de ánimo de consenso y conciliación, al mayor número posible de votantes que el 5 de mayo le rindieron su voto útili87. Asimismo en la cartera de Interior nombra a Nicolás Sarkozy ${ }^{188}$, hombre fuerte del "gobierno electoral" creado tras la segunda vuelta de las elecciones presidenciales para conducir la batalla de las legislativas ${ }^{189}$.

Inmediatamente después del nombramiento de su nuevo Gobierno, Chirac, consciente del carácter provisional de éste último, empieza a dar muestras de la puesta en práctica de su programa, sabedor de que ésta es la mejor forma de hacer campaña para las legislativas, $y$ anuncia reformas próximas ${ }^{190}$, como la que urge en materia de pensiones, así como ciertas reformas institucionales, a saber, el fortalecimiento del control del Parlamento, la reducción del mandato de los senadores, o el examen del estatuto penal del Jefe del Estado (art. 68 de la $C)^{191}$. En materia de seguridad urge a su gobierno para que prepare leyes contra la inseguridad en el plazo de diez días ${ }^{192}$. En el res-

\footnotetext{
183. Cfr. Le Monde, 08.05.02, pág. 8 .

184 Cfr. Ídem, pág. 1. Asimismo cfr. El Mundo, 08.05.02, pág. 22.

185 Cfr. El País, 08.05.02, pág. 4.

186 Cfr. Le Monde, 17.04.02.

187 En este sentido, cfr. The Daily Telegraph, 07.05.02, pág. 10.
}

188 Este ministerio, que amplía sus competencias, pasa a llamarse «Ministerio de Seguridad Interior y libertades locales" (cfr. Le Monde, 09.05.02, pág. 7). Chirac recupera nuevamente a este hombre, ex secretario general de la RPR, cuyo apoyo a Balladur en las elecciones presidenciales de 1995 le valió su postergación durante cuatro años. Chirac ha adoptado en su programa las proposiciones de su libro Libre (cfr. Le Monde, 08.05.02).

189 Cfr. El Mundo, 01.05.02, pág. 4, y $A B C, 08.05 .02$, pág. 32.

190 Cfr. El Mundo, 06.05.02, pág. 5.

191 Cfr. Le Monde 08.05.02, pág. 7.

192 Cfr. El Pais, 07.05.02, pág. 3, y $A B C, 11.05 .02$, pág. 28. 
to de temas pendientes, destaca la voluntad anunciada del Gobierno de no interferir en las causas judiciales, si bien, en contraste con el gobierno Jospin, que prohibió dar instrucciones a los fiscales en los expedientes individuales, Dominique Perben, nuevo Ministro de Justicia, reserva esta abstención sólo para los asuntos político-financieros $^{193}$. Como puesta en práctica de la urgente reforma anunciada de la Justicia, el nuevo titular de este ministerio anuncia una ley de medios para la Justicia, que abordará el modo de provisión al cargo, la justicia de proximidad, la creación de centros cerrados para menores delincuentes y la posible construcción de nuevas prisiones ${ }^{194}$. Nicolás Sarkozy también anuncia medidas inmediatas para garantizar la seguridad ciudadana y Raffarin, por su parte, anuncia una auditoría de las finanzas públicas ${ }^{195}$ y manifiesta querer reanudar el diálogo social con los sindicatos ${ }^{196}$. Finalmente, para recoger este ánimo de reforma urgente en el seno del gobierno de la UMP, Raffarin lanza un programa titulado "Veinticinco compromisos para Francia con Jacques Chirac", destinado a reforzar la unión en el seno de la UMP197. Paralelamente al anuncio de estas medidas, Chirac se esfuerza en condenar la cohabitación, que provoca, según él, la «neutralización de las energías" y pide una "verdadera mayoría" para adoptar las reformas prometidas ${ }^{198}$.

193 En este sentido resulta de utilidad mencionar que el gobierno Jospin había instaurado de hecho una autonomía del Ministerio Público y que esta renuncia a intervenir debía ser objeto de una reforma judicial que, iniciada por el Jefe del Estado en 1996, topó finalmente con la hostilidad de la derecha, para finalmente ser aplazada por Chirac a comienzo del 2000. Cfr. Le Monde, 16.05.02, pág. 9. Respecto de las causas en las que estén implicados los ministros, Raffarin abandona la llamada "jurisprudencia Bérégovoy», según la cual todo ministro implicado en una causa judicial debia abandonar inmediatamente el Gobierno. Raffarin, por el contrario, se declara partidario de aplicar el principio de presunción de inocencia (cfr. Le Monde, 17.05.02, pág. 8).

194 En relación con este tema, en principio debería de mantenerse la ley sobre la presunción de inocencia lobjeto de fue te polémica entre el PS y la derecha). Cfr. Le Monde, 16.05.02, pág. 9.

195 Cfr. El Mundo, 09.05.02, pág. 24.

196 FO (Fuerza Obrera), por su parte, deılara que no aceptará que la duración de las cotizaciones se alargue a cuarenta años. Este sindicato está en contra del sistema de capitalización de las pensiones y se declara partidario de aumentar el porcentaje dedicado a repartición (cfr. Le Monde, 17.05.02, pág. 7).

197 Cfr. Le Monde, 24.05.03, pág. 7. Asimismo, Le Monde 07.06.02, pág. 6, destaca que Raffarin promete realizar una nueva reforma "cada dos o tres meses".

198 Así lo hace, por ejemplo, el 5 de junio durante una alocución televisiva en France 3 (cfr. Le Monde, 07.06.02, págs. 1 y 6). 
En cuanto a los otros socios de la UMP, señalaremos que la UDF sigue presentándose como formación propia. Bayrou, que deja su escaño de diputado europeo, piensa que sigue siendo necesaria la existencia de un segundo polo correspondiente a la derecha centrista $y$, por consiguiente, tiene la intención de defender a la UDF en un máximo de circunscripciones, a excepción de aquellas en las que el Frente Nacional represente un peligro ${ }^{199}$. Sin embargo, debido a la masiva emigración de ex diputados de la UDF hacia la UMP, se ve obligado, incapaz de cubrir todo el territorio nacional, a sostener candidaturas ya presentadas bajo las siglas de la UMP, sobre todo en París. Por el contrario el presidente de DL, Alain Madelin, se presenta en su circunscripción de Ille-et-Vilaine, con el apoyo de la UMP200. También concurrirá por separado otra formación de derechas, el Movimiento por Francia (MPF). Su líder, Philippe de Villiers, argumenta para ello que los resultados del 21 de abril han mostrado que la derecha retrocede cuando no cubre todo su espectro político ${ }^{201}$. También presenta sus propios candidatos el partido que lidera Corine Lepage (CAP 21) y el de Charles Pasqua, Reagrupación por Francia (RPF).

Pese a esta presentación de candidaturas separadas por parte de los socios de la UMP, la unión de la derecha es consistente, sobre todo por comparación con la división existente en las filas izquierdistas. Los sondeos atribuyen a la derecha un $55 \%$ de intención de voto ${ }^{202}$. Además, ésta tiene a su favor la inercia creada por el resultado final de las elecciones presidenciales y que el electorado parece no desear una nueva cohabitación ${ }^{203}$.

\section{II.2. Izquierda}

Tras pedir el voto de la izquierda socialista para Chirac, el Partido Socialista intenta reagrupar a sus electores de cara a las legislativas. El Primer secretario del partido, François Hollande, manifiesta su deseo de que la izquierda presente un candidato único desde la primera vuelta en ciertas circunscripciones ${ }^{204}$. Simultáneamente, en el

199 Cfr. Le Monde 15.05.02, pág. 10.

200 Cfr. idem, id.

201 EI MPF presenta 325 candidaturas a las elecciones legislativas (cfr. ídem, id., pág. 10).

202 Cfr. Le Monde, 22.05.02, pág. 8.

203 Cfr. ídem, id.

204 Cfr. Le Monde 23.03.02, pág. 8, y El País, 10.05.02, pág. 9. 
seno del partido se examinan los errores cometidos en la campaña electoral 205 , entre los cuales se mencionan la necesidad de desmarcarse de Chirac tras cinco años de cohabitación ${ }^{206}$, el presentar un programa demasiado centrista ${ }^{207}$, ejemplo de lo cual es, entre otras cosas, no haber hecho excesivo hincapié en los derechos de los trabajadores, como suele ser propio de un programa de izquierdas, algunos ataques directos poco fundamentados políticamente a la persona de Chirac ${ }^{208}$ o haber abandonado el tema de la inseguridad ${ }^{209}$. Pero sobre todo se subraya el error de haber resaltado demasiado las diferencias, olvidando lo que hay de común en la familia socialista ${ }^{210}$. Asimismo los socialistas cambian el discurso mantenido durante la campaña para las presidenciales, redactando un programa en el que intentan un giro desesperado a la izquierda, en el que resaltan las medidas sociales ${ }^{211}$, al tiempo que se declaran partidarios de una cohabitación como mal menor, dado que consideran la UMP una amalgama política incongruente, sin capacidad real de gobierno212. Simultáneamente comienzan a realizar negociaciones para estos segundos comicios con sus socios de la izquierda plural, el PRG, lo\$ Verdes y el PCF, si bien éste estima insuficientes las proposiciones lel Partido socialista para las legislativas del 9 y 16 de junio ${ }^{213}$. Mientras tanto los Verdes hacen hincapié en su deseo de reformar la sociedad, manifestando que crisis social y ecología están unidas, razón por la que la ecología es de izquierdas ${ }^{214}$. Finalmente, bajo el nombre de "izquierda plural" el PS, el PCF, los Verdes, y el PRG llegan a un acuerdo de renuncia a favor

205 Cfr. Le Monde, 24.04.02, pág. 7.

206 En efecto, esto es algo complicado, dado que en periodo de coexistencia de mayorías el verdadero gestor de la nación es el jefe del gobierno (en este caso el socialista Lionel Jospin) mientras que el presidente pierde la mayoría de sus competencias y por lo tanto, cualquier ataque a la gestión de la nación equivale a reconocer una mala gestión del gobierno.

207 En efecto, el 21 de febrero declaraba: "Mi proyecto no es socialista" (cfr. ídem, id.). Asimismo véase la entrevista de Jospin concedida a Le Monde, publicada el 02.03.2002, págs. 1 y 6.

208 Reprocha a Chirac estar "viejo y cansado" (cfr. ídem, id.).

209 En efecto el 28 de marzo Jospin abandona el tema de la inseguridad y reprocha a Chirac utilizarlo tan vigorosamente como un Ministro del Interior (cfr. idem, id.).

210 Cfr. opinión de DeLANÖE, alcalde de París (PS) en ídem, id.

211 Cfr. $A B C, 08.05 .02$, pág. 33, y El Mundo, 08.05.02.

212 Cfr. Ídem, id., y Le Monde, 25.05.02, pág. 6.

213 Cfr. Le Monde, 08.05.02, pág. 7.

214 El 7 de mayo publican un libro con su programa para llevar a cabo esa reforma (cfr. Le Monde, 08.05.02, pág. 8). 
del candidato de cabeza, si bien aún falta acuerdo en algunas circunscripciones ${ }^{215}$, acuerdo en el que no participa Jean-Pierre Chevènement, tras haber sido rechazada la propuesta de unión realizada al PS el mismo 5 de mayo, tras conocer los resultados obtenidos en la segunda vuelta de las elecciones presidenciales ${ }^{216}$. Finalmente hay que apuntar que la situación para la izquierda es algo esperanzadora en París, donde todavía persiste el "efecto Delanöe» de las pasadas elecciones municipales, en las que se confirmó el giro a la izquierda de la capital iniciado en las elecciones legislativas de 1997.

EI PCF por su parte deberá enfrentarse en estas elecciones a disidentes de la ortodoxia comunista. En cuanto al PCF, su líder, Robert Hue, deberá luchar por conservar su escaño de diputado del Val-d'Oise, donde no tendrá que afrontar la disidencia de ningún candidato comunista. Sí en cambio en otras circunscripciones, en las que deberá enfrentarse a otros candidatos comunistas ortodoxos que se niegan a seguir llevando el sombrero del líder del PCF, habida cuenta del ridículo porcentaje de votos conseguido en las presidenciales ${ }^{217}$. Su objetivo inmediato en vísperas de la primera vuelta es salvar su grupo en la AN218.

\section{II.3. Extrema izquierda y ecologistas}

Los dos partidos trotskistas, LO y LCR, irán por separado a estos comicios $^{219}$. Olivier Besancenot (LCR) espera que las legislativas delimiten definitivamente las dos izquierdas. Además concurren a estas elecciones Lucha Obrera (LO) y el Partido de los Trabajadores (PT).

Asimismo destaca el elevado número de formaciones ecologistas, de las que la mejor situada es el partido de los Verdes, que obtuvo un $5,25 \%$ en la primera vuelta de las presidenciales. Desde las elecciones municipales de 2001 se ha convertido en un eventual aliado útil del PS.

215 Cfr. Le Monde, 19 y 20 de mayo de 2002, pág. 6. La izquierda plural presenta 176 candidaturas de unión, pero no tendrá un candidato único más que en 34 circunscripciones (cfr. Le Monde, 22.05.02, pág. 1).

216 Cfr. Le Monde, 08.05.02, pág. 8, y 30.05.02, pág. 11.

217 La situación es particularmente difícil para Robert Hue en Corrèze, en cada una de cuyas tres circunscripciones se presenta, junto con un candidato del PCF, otro candidato próximo de la Coordinación de militantes comunistas (cfr. Le Monde, 23.05.02, pág. 9).

218 Cfr. Le Monde, 08.06.02, pág. 7.

219 Arlette Laguiller (LO) acusa a Olivier Besancent (LCR) el haber dado una consigna indirecta de voto a Chirac en las presidenciales. 


\section{II.4. Extrema derecha}

El Frente Nacional, que se ve obligado a presentar candidatos en todas las circunscripciones, a excepción de en Strasbourg-Sud, donde sostiene a Robert Spieler, del Movimiento regionalista de Alsacia (MRA), espera celebrar acuerdos de desistimiento con la derecha, esperando multiplicar los casos de duales o triangulares, si bien descarta cualquier alianza con Bruno Mégret ${ }^{220}$.

\section{II.5. Conclusiones}

Resumiendo, en la víspera de la primera vuelta de estos comicios la situación puede resumirse del siguiente modo:

- Existencia de una unión relativamente coherente en la derecha, si bien sigue habiendo disidencias. Además la derecha goza de una posición ventajosa propiciada por los resultados de las elecciones presidenciales. El nombramiento por Chirac del nuevo gobierno y la puesta en práctica de las primeras medidas anunciadas en la campaña de las elecciones presidenciales le han permitido ofrecer una campaña en estas legislativas basada en hechos y no en meras promesas.

- Desunión en la izquierda, no sólo por la exclusión de Chevènement, sino también por la total separación de los partidos de extrema izquierda, que parecen haber acaparado casi todos los votos del PCF, motivando que éste deje de ser una cantera de votos suplementaria para el PS, deviniendo así un aliado inútil. La posición de la que parte la izquierda moderada es de clara desventaja, por la desunión apuntada, por la victoria de la derecha en las elecciones presidenciales, que tiene vocación de confirmarse en las legislativas, debido al cansancio del electorado de cinco años de cohabitación, y por la poca movilización del electorado de izquierdas acusada en las citadas elecciones presidenciales.

- Incertidumbre sobre lo que ocurrirá en las legislativas con el FN. La dispersión del voto podría hacer que tuviera que vérselas con la UMP y con la izquierda plural en muchas situa-

220 Cfr. Le Monde, 08.05.02, pág. 10, y 15.05.02, pág. 10. Asimismo cfr. Le Monde, 9-10 de junio de 2002, pág. 7 . 
ciones de duales o triangulares. Sin embargo este tipo de comicios nunca han sido demasiado favorables para el FN, que, debido a su escasa estructura, se desenvuelve mejor en las elecciones presidenciales si bien, en compensación, cuenta con un electorado muy organizado y poco absentista.

\section{II.6. Otros temas de interés}

Finalmente expondremos otras características que nos parecen relevantes en relación con estas elecciones.

- El olvido de la regla de la paridad entre hombres y mujeres, instituida por Ley n. ${ }^{\circ}$ 2000-49 de 6 de junio de 2000 en municipios con 3.500 habitantes o más y aplicada por vez primera en las elecciones municipales de 2001. En estos comicios esta regla se ha relegado a un segundo plano. Por ejemplo, dentro de la UMP sólo hay un $20 \%$ de candidaturas sostenidas por mujeres ${ }^{221}$.

- Asimismo los ministros parecen haber dejado de lado la regla anti-acumulación iniciada por Jospin. Chirac, en coherencia con las manifestaciones anti-acumulación de funciones ejecutivas realizada en $1997^{222}$, ha pedido a los miembros del Gobierno que renuncien a sus escaños locales. Varios ya han dimitido, pero otros, la mayoria, han adoptado disposiciones para recuperar su escaño en caso de fracaso de la derecha en estos comicios. Raffarin tendrá que imponerla aunque le pese a los miembros del Gobierno, si quiere ser coherente con la defensa de la antiacumulación realizada por Chirac.

- Otra característica de estos comicios es el elevado número de candidaturas, que ha alcanzado el número de 8.633 en la primera vuelta, superando así en un tercio el récord de 1997. La mayor dispersión se encuentra en la izquierda, donde destaca el elevado número de candidaturas ecologistas. A continuación exponemos la distribución ideológica de las formaciones que concurren a estas elecciones: 


\section{FORMACIONES CONCURRENTES}

A LAS ELECCIONES LEGISLATIVAS FRANCESAS

DE $2002^{223}$

\begin{tabular}{|c|c|c|}
\hline $\begin{array}{l}\text { Extrema } \\
\text { izquierda }\end{array}$ & $\begin{array}{l}\text { LCR } \\
\text { LO } \\
\text { PT } \\
\text { SEGA }\end{array}$ & $\begin{array}{l}\text { (Liga Comunista Revolucionaria) } \\
\text { (Lucha Obrera) } \\
\text { (Partido de los Trabajadores) } \\
\text { (Solidaridad, Ecología, Izquierda Alternativa) }\end{array}$ \\
\hline Izquierda & $\begin{array}{l}\text { C. Cit. } \\
\text { PC } \\
\text { PRG } \\
\text { PS }\end{array}$ & $\begin{array}{l}\text { (Concordato Ciudadano) } \\
\text { (Partido Comunista) } \\
\text { (Partido Radical de Izquierda) } \\
\text { (Partido Socialista) }\end{array}$ \\
\hline Republicanos & $\begin{array}{l}\text { IR } \\
\text { P. Rép. }\end{array}$ & $\begin{array}{l}\text { (Iniciativa Republicana) } \\
\text { (Polo Republicano) }\end{array}$ \\
\hline Ecologistas & $\begin{array}{l}\text { CAP } 21 \\
\text { CEI } \\
\text { GE } \\
\text { MEI } \\
\text { MHAN } \\
\text { NE } \\
\text { RE } \\
\text { Verdes }\end{array}$ & $\begin{array}{l}\text { (Ciudadanía, Acción y Participación para el Siglo XXI) } \\
\text { (Confederación de Ecologistas Independientes) } \\
\text { (Generación Ecología) } \\
\text { (Movimiento Ecologista Independiente) } \\
\text { (Movimiento Hombres, Animales, Naturaleza) } \\
\text { (Nuevos Ecologistas) } \\
\text { (Renovación Ecologia) } \\
\text { (Los Verdes) }\end{array}$ \\
\hline Regionalistas & RPS & (Regiones y Pueblos Solidarios) \\
\hline $\begin{array}{l}\text { Formaciones } \\
\text { procedentes } \\
\text { de grupos } \\
\text { de presión }\end{array}$ & $\begin{array}{l}\text { ED } \\
\text { Gipda } \\
\text { PF. } \\
\text { RCF } \\
\text { RND }\end{array}$ & $\begin{array}{l}\text { (Energias Demócratas) } \\
\text { (Agrupación de Interés Político-Democrático Activo) } \\
\text { (Partido Federalista) } \\
\text { (Reagrupación de Contribuyentes Franceses) } \\
\text { (Réseau Nouvelle Donne) }\end{array}$ \\
\hline Cazadores & $\begin{array}{l}\text { CPNT } \\
\text { DDC }\end{array}$ & $\begin{array}{l}\text { (Caza, Pesca, Naturaleza y Tradiciones) } \\
\text { (Derecho de Caza) }\end{array}$ \\
\hline Derecha & $\begin{array}{l}\text { CNI } \\
\text { MPF } \\
\text { UDF } \\
\text { UMP }\end{array}$ & $\begin{array}{l}\text { (Centro Nacional de los Independientes) } \\
\text { (Movimiento por Francia) } \\
\text { (Unión por la Democracia Francesa) } \\
\text { (Unión por la Mayoría presidencial) }\end{array}$ \\
\hline $\begin{array}{l}\text { Extrema } \\
\text { derecha }\end{array}$ & $\begin{array}{l}\text { FN } \\
\text { MNR }\end{array}$ & $\begin{array}{l}\text { (Frente Nacional) } \\
\text { (Movimiento Nacional Republicano) }\end{array}$ \\
\hline
\end{tabular}


- Finalmente señalaremos el escaso origen inmigrante de los candidatos. De los 8.424 candidatos que se presentan en la primera vuelta de las elecciones legislativas, sólo 123 son franceses de origen africano o magrebí224. El auge de las ideas del FN en el seno del electorado francés y la importancia cobrada por el tema de la seguridad en estas elecciones no parece favorecer la promoción de este tipo de candidatos.

\section{LA PRIMERA VUELTA DE 9 DE JUNIO}

Los resultados en la primera vuelta de las elecciones legislativas son los siguientes:

\section{RESULTADOS EN VOTOS EXPRESADOS ${ }^{225}$}

\begin{tabular}{|c|c|c|}
\hline $\begin{array}{l}\text { Inscritos: } \\
\text { Abstenciones: } \\
\text { Votantes: } \\
\text { Blancos o nulos: } \\
\text { Expresados: }\end{array}$ & $\begin{array}{r}40.968 .484 \\
14.578 .609 \\
26.389 .875 \\
1.143 .830 \\
25.246 .045\end{array}$ & $\begin{array}{l}100 \% \\
35,58 \% \text { de los inscritos } \\
64,42 \% \text { de los inscritos } \\
2,79 \% \text { de los inscritos } \\
4,33 \% \text { de los votantes } \\
61,62 \% \text { de los inscritos }\end{array}$ \\
\hline Familias politicas & Número de votos obtenidos & Sufragios expresados en \% \\
\hline LO & 301.984 & $1,20 \%$ \\
\hline LCR & 320.467 & $1,27 \%$ \\
\hline Extrema izquierda & 81.558 & $0,32 \%$ \\
\hline PCF & 1.216 .178 & $4,82 \%$ \\
\hline PS & 6.086 .599 & $24,11 \%$ \\
\hline PRG & 388.891 & $1,54 \%$ \\
\hline Izquierda diversa & 275.553 & $1,09 \%$ \\
\hline Verdes & 1.138.222 & $4,51 \%$ \\
\hline Polo Republicano & 299.897 & $1,19 \%$ \\
\hline Otros ecologistas & 295.899 & $1,17 \%$ \\
\hline
\end{tabular}




\begin{tabular}{lcc}
\hline Familias políticas & Número de votos obtenidos & Sufragios expresados en \% \\
\hline Regionalistas & 66.240 & $0,26 \%$ \\
\hline CPNT & 422.448 & $1,67 \%$ \\
\hline Diversas & 194.946 & $0,77 \%$ \\
\hline UMP & 8.408 .023 & $33,30 \%$ \\
\hline UDF & 1.226 .462 & $4,85 \%$ \\
\hline DL & 104.767 & $0,41 \%$ \\
\hline RPF & 94.222 & $0,37 \%$ \\
\hline MPF & 202.831 & $0,80 \%$ \\
\hline Derecha diversa & 921.973 & $3,65 \%$ \\
\hline FN & 2.862 .960 & $11,34 \%$ \\
\hline MNR & 276.376 & $1,09 \%$ \\
\hline Extrema derecha & 59.549 & $0,24 \%$ \\
\hline
\end{tabular}

Las notas más relevantes de los resultados de esta primera vuelta son los siguientes:

- La polarización hacia las familias políticas más importantes, principalmente UMP y PS, que contrasta con la gran dispersión observada en la primera vuelta de las presidenciales.

- La elevada abstención (35,58\%), que supera los niveles de la primera vuelta de las presidenciales $(30,82 \%)$, abstención que afecta principalmente a los partidos de izquierda.

- El claro retroceso de la extrema derecha, que no confirma el ascenso experimentado en las presidenciales. EI FN, que no consigue llegar en cabeza en ninguna circunscripción, obtiene sólo un $11,34 \%$ ( 12,43 el total de la extrema derecha), frente al $16,86 \%(19,20 \%)$ de las elecciones presidenciales $y$ el $14,9 \%(15,10 \%)$ de las elecciones legislativas de 1997 . Se confirma con esto la dificultad del FN en este tipo de elecciones, que obedece principalmente a la fragmentación del paisaje político, al multiplicarse los frentes en los que debe competir, dificultad ésta que se acentúa en unas elecciones munici- 
pales226. Además el FN también ha acusado un fuerte abstencionismo de su electorado y la fuga de votos hacia la UMP.

- La derecha gana esta primera vuelta, si bien sin el amplio margen conseguido en las elecciones de 1993, en las que obtuvo 472 escaños de los 577 del Palais Bourbon. Los relativamente buenos resultados ahora, que confirman el desenlace de las presidenciales, combinados con los malos resultados del FN (en la segunda vuelta figurará sólo en treinta y siete circunscripciones) le permiten aspirar a conseguir la mayoría absoluta en la segunda vuelta de estas elecciones concentrándose en los casos de duales con la izquierda.

- La izquierda pierde en esta primera vuelta. EI PS no logra movilizar a su electorado. Conserva gran parte de sus circunscripciones en el suroeste de Francia y algunas otras en el centro, noreste y noreste. Ello le valdría conservar 111 escaños, si bien apenas podrá contar con un aporte suplementario de votos, habida cuenta del débil resultado conseguido por los Verdes y el Polo Republicano y el PRG227. En París el PS y Los Verdes vencen a la derecha con doce circunscripciones frente a nueve, confirmando asi la tendencia iniciada en las municipales del año anterior. Sin querer reconocer todavía su derrota, el PS hace una llamada a los electores a movilizarse en la segunda vuelta.

- El Partido Comunista francés confirma su retroceso al obtener solamente $4,82 \%$ de los votos, frente al $9,88 \%$ obtenido en las legislativas de 1995, si bien su resultado es algo superior al obtenido en las presidenciales $(3,37 \%)$. Sólo treinta y siete candidatos estarán en condiciones de pasar a la segunda vuelta. En este caso podría conseguir diecinueve escaños, lo que le permitiría constituir una futura agrupación en la Asamblea Nacional.

226 Este fenómeno también se produjo en las presidenciales y legislativas de 1988, también tras un periodo de cohabitación. En este sentido véase Le Monde, 12.06.02, pág. 6 .

227 En este sentido véase la editorial de Le Monde de 12.06.02, pág. 19, donde se constata que, a diferencia de las elecciones de 1995, en las que el objetivo era utilizar a los actores de la izquierda plural para relegitimar al partido socialista, ahora se busca el resultado inverso, es decir: es el Partido Socialista el que debe recapitalizar la izquierda o, utilizando las palabras de François Hollande, el mantenimiento del PS debe hacerse en detrimento de sus socios de la izquierda plural. 


\section{LA SEGUNDA VUELTA DE 16 DE JUNIO}

\section{RESULTADOS EN VOTOS EXPRESADOS 228}

\begin{tabular}{lcr}
\hline Inscritos: & 36.783 .746 & $\begin{array}{r}100 \% \\
\text { Abstenciones: }\end{array}$ \\
Votantes: & $\begin{array}{l}22.1867 .581 \\
\text { Blancos o nulos: }\end{array}$ & $\begin{array}{r}39,68 \% \text { de los inscritos } \\
60,32 \% \text { de los inscritos } \\
2,62 \% \text { de los inscritos } \\
4,35 \% \text { de los votantes }\end{array}$ \\
Expresados: & 21.221 .026 & $57,69 \%$ de los inscritos \\
\hline Familias políticas & Número de votos obtenidos & Sufragios expresados en $\%$ \\
\hline PCF & 690.807 & $3,26 \%$ \\
\hline PS & 7.482 .169 & $35,26 \%$ \\
\hline PRG & 455.360 & $2,15 \%$ \\
\hline Izquierda diversa & 268.715 & $1,27 \%$ \\
\hline Verdes & 677.933 & $3,19 \%$ \\
\hline Polo Republicano & 12.679 & $0,06 \%$ \\
\hline Regionalistas & 28.689 & $0,14 \%$ \\
\hline Diversas & 13.036 & $0,06 \%$ \\
\hline UMP & 10.029 .669 & $47,26 \%$ \\
\hline UDF & 832.785 & $3,92 \%$ \\
\hline RPF & 61.605 & $0,29 \%$ \\
\hline Derecha diversa & 274.374 & $1,29 \%$ \\
\hline FN & 393.205 & $1,85 \%$ \\
\hline
\end{tabular}

Los resultados más relevantes de esta segunda vuelta son los siguientes:

- La elevada abstención $(39,71 \%)$, la mayor registrada en la segunda vuelta en unas elecciones legislativas.

- Los datos confirman las dificultades de Le Pen en este tipo de elecciones y el cierre del paso a la extrema derecha pro-

228 Fuente: Ministerio del Interior. Datos suministrados por la Embajada de Francia en España. 
piciado por el elevado abstencionismo de la extrema derecha en esta segunda vuelta y la movilización de una parte de este electorado hacia la UMP y hacia partidos de izquierda. Como resultado el líder del FN no consigue ningún escaño en la Asamblea.

- La UMP supera con mucho el límite necesario de la mayoría absoluta. Esta victoria no es tan arrolladora como la de 1993 (472 diputados RPR y UDF), pero sobrepasa ligeramente la del general de Gaulle tras los hechos de 1968 (387 elegidos UDR y centristas) ${ }^{229}$. La UDF, por su parte, se ve absorbida en buena parte por la UMP (29 escaños frente a los 67 que tenía en la anterior Asamblea).

- EI PS pierde más de cien escaños (finalmente sólo tendrá 141 de los 248 de que disponía), pero con la diferencia de que ahora sus socios están más debilitados, ya que el PCF consigue sólo 21 escaños (22 junto con los republicanos).

Finalmente, la composición de la Asamblea, con el total efectivo de grupos y tras las alianzas correspondientes, es, en la. fecha de 25 de junio, la siguiente:

\begin{tabular}{lrllc}
\hline \multicolumn{2}{c}{ ASAMBLEA SALIENTE } & \multicolumn{2}{c}{ NUEVA ASAMBLEA } & \\
\hline Familia o grupo político & $N .^{\circ}$ escaños & Familia o grupo político & $N^{\circ}$ escaños \\
\hline Partido Socialista (PS) & 248 & Socialista & 141 \\
\hline Partido Comunista (PC) & 35 & Comunistas y Republicanos & 22 \\
\hline RCV (Radical, Ciudadano y Verde) & 31 & & \\
\hline Alianza UDF & 67 & UDF & 29 \\
\hline Democracia Liberal & 43 & & \\
\hline RPR & 135 & UMP & 365 \\
\hline No inscritos & 5 & No inscritos & 20 \\
\hline Escaños vacantes & 13 & Escaños vacantes & 0 \\
\hline Total escaños & 577 & Total escaños & 577 \\
\hline
\end{tabular}

229 Cfr. Le Monde, 18.06.02, pág. 10.

230 Fuente: Asamblea Nacional, publicada en Le Monde, 11.06.02.

231 Fuente: Asamblea Nacional. Datos facilitados por la Embajada de Francia en España. 


\section{CONCLUSIONES Y VALORACIÓN JURÍDICO-POLIITICA}

V.1. La larga tormenta electoral francesa, iniciada con los desconcertantes resultados de la primera vuelta de las elecciones presidenciales, en la que se ha alzado vehemente la protesta de una buena parte del electorado, insatisfecha por no hallar respuesta a sus problemas individuales o inmediatos, concluye ahora sin embargo con la victoria arrolladora de la $\mathrm{V}$ República en su forma más clásica y convencional, concentrando todos los poderes en las manos de un solo hombre, Jacques Chirac, que deviene así Presidente de derecho y jefe de gobierno de hecho, en virtud de la lógica constitucional iniciada en 1958. Los franceses parecen confirmar con ello que lo sucedido el 21 de abril era sólo una llamada de atención a sus gobernantes. Aprendida la lección por éstos, los electores parecen confirmar que desean certeza y seguridad ${ }^{232}$. En efecto, tras la alarma suscitada en la primera vuelta de las elecciones presidenciales, tras la que se temió que el FN se convirtiera en el nuevo árbitro de las elecciones nacionales, resulta paradójico que el desenlace final de esta batalla electoral esté en las antípodas de lo que las predicciones iniciales hacían temer y que la elección haya recaído finalmente en la coherencia institucional, tras tres años de cohabitación. El gran vencedor ha sido desde luego Jacques Chirac, que tras una larga campaña contra la inseguridad ciudadana iniciada el 14 de julio de 2001, campaña que sirvió para nutrir la capacidad de atracción del Frente Nacional, se ha erigido en árbitro nacional para preservar la República, obligando incluso a la izquierda a rendirle su voto.

V.2. Los resultados iniciales del 21 de abril también denotan la insatisfacción y apatía del electorado, no sólo por la gran dispersión de su voto, sino también por el alto índice de abstención, muy elevado para tratarse de unas elecciones presidenciales. Los hechos indican que el origen de esta abstención es múltiple. En primer lugar, está la poca diferencia existente entre los programas de los dos principales contendientes, Chirac y Jospin, algo lo que no facilita la movilización. En segundo lugar está la inseguridad social y el desánimo del electorado, que ya no confía en sus dirigentes para que le solucionen sus problemas y se vuelve apolítico o, por el contrario, busca en los extremismos la solución a sus problemas. Finalmente, en tercer lugar, está el hecho de que una buena parte de abstencionistas es de índole 
coyuntural, es decir, sólo se moviliza cuando hay algo importante en juego (ejemplo ilustrativo de esta afirmación lo encontramos en la baja abstención registrada el $\mathbf{5}$ de mayo). Lo verdaderamente preocupante en este caso es que la elevada abstención registrada el 21 de abril haya hecho posible que un electorado extremista organizado haya alterado completamente el juego normal electoral.

V.3. La derecha, finalmente vencedora, deberá sacar provecho de esta lección y realizar las medidas urgentes prometidas. La más difícil será sin duda la financiera. A Chirac le resultará difícil cumplir con lo prometido, dado que su oferta, realizada durante la campaña de las presidenciales en el marco de una especie de carrera de "quién da más» es considerada por los analistas como demasiado optimista ${ }^{233}$. Para otros, la amplia mayoría con la que la derecha ha vencido pone en tela de juicio la prometida adopción de reformas ${ }^{234}$.

V.4. Asimismo todo parece indicar, tras los resultados del 16 de junio, que la UMP impondrá su partido a la derecha, como ya ha dado muestras antes de esta segunda vuelta, Los nuevos «barones» de la UMP serán los cuatro líderes que han jugado un papel determinante en la campaña a favor de la UMP, una vez descartados François Bayrou y Alain Madelin (Séguin fue neutralizado tras su fracaso en las municipales del año pasado), a saber: Philippe Douste-Blazy, MM Fillon, Raffarin y Juppé. Para ello, la RPR y DL tendrán que liquidar el aparato de su partido ${ }^{235}$. François Bayrou y el soberanista Phillippe de Villiers (MPF) rechazan sumarse a la nueva agrupación. Este último figurará entre el grupo de los no inscritos, mientras que la UDF de Bayrou pone "al mal tiempo buena cara" y señala que la independencia de la UMP dará a este grupo una mayor libertad de palabra, mientras que, en caso de crisis, siempre se deberá contar con él como viajero del «mismo barco» ${ }^{236}$.

V.5. Asimismo la nueva composición de la AN muestra el fracaso en las elecciones legislativas de la regla sobre la paridad. Rele-

233 Cfr. The Economist, 22.06.02, pág. 31.

234 Por ejemplo, cfr. The Herald Tribune, 17.06.02, págs. 1 y 7, y The Economist, 22.06.02, pág. 13.

235 Cfr. Le Monde, 14.06.02. El nuevo dirigente de este nuevo partido UMP será Alain Juppé.

236 Cfr. ídem, id. 
gada esta regla a un segundo plano en la elaboración de las listas para las elecciones legislativas, finalmente la nueva Asamblea sólo contará con seis mujeres más que en 1997.

V.6. Otro dato que nos parece digno de resaltar es el siguiente: a la enorme dispersión del voto en la primera vuelta de las presidenciales, ha seguido una tendencia al bipartidismo en torno a los dos principales contendientes: el PS, que pasa a liderar bajo sus siglas a la izquierda, y la UMP, que pasa a engrosar sus filas con DL y con buena parte de los diputados de la UDF. Esta situación se ha visto sin embargo amortiguada por el salvamento in extremis del PCF y por el mantenimiento de la UDF en la Asamblea237.

V.6. El desenlace de estas dobles elecciones parece indicar que Francia ha girado a la derecha, si se compara la nueva situación con la resultante de las elecciones legislativas de 1997238. Esto es cierto, siempre que consideremos que la era Chirac terminó con las elecciones legislativas de 1997. Sin embargo, para algunos analistas no ha habido tal giro y la era de la derecha (que siguió con soluciones de continuidad a la era Mitterrand) no ha terminado todavia. Según esta opinión, la victoria de la izquierda en las elecciones legislativas de 1997 sería sólo un paréntesis en esta época de dominación de la dérecha ${ }^{239}$.

Así, para algunos como Max Gallo, la derrota de Jospin se debe a una victoria de Chirac en las elecciones de 1997, llegada con retraso y Jospin no ha sido sino una transición que ha puesto fin a la era Mitterrand ${ }^{240}$. Lo expuesto indica que la derecha deberá recordar la lección de 1997 y actuar rápidamente, pero de forma tranquila, evitando dar síntomas de desunión y, sobre todo, de prepotencia.

237 Cfr. Le Monde, 18.06.02, pág. 20.

238 Cfr. The Economist, 22.06.02, pág. 31.

239 La victoria de la izquierda en las legislativas de 1997 se atribuye a la elevada abstención del electorado frente a una medida que carecia de fundamento político o social, a la buena movilización en aquella época de la izquierda, en cuyo seno soplaban vientos de renovación y, por último, a la incertidumbre de otra parte del electorado sobre si confirmar el apoyo dado inicialmente a Chirac. Cfr. La France aux urnes, op. cit., pág. 28. La disolución de la Asamblea Nacional en 1997 también se consideró una manifestación de arrogancia (cfr. The Economist 22.07.02, pág. 32).

240 Cfr. Corriere della Sera, 10.06.02, pág. 2. 